Argonne

\title{
Water Issues Associated with Heavy Oil Production
}

Environmental Science Division 


\title{
Acknowledgements
}

The authors wish to express their appreciation to Jesse Garcia of DOE's National Energy Technology Laboratory, who provided the funding for this project. We also acknowledge the support and encouragement for this project that was provided by Todd Ririe of BP and Jill Kerr of ExxonMobil. They are the current (Ririe) and past (Kerr) chairpersons of the Petroleum Environmental Research Forum (PERF). Their endorsement of this effort was instrumental in obtaining funding for the project.

We owe a great debt of gratitude to Maurice Dusseault of the University of Waterloo in Ontario, Canada. Professor Dusseault has published many papers and reports on heavy oil activities throughout the world. In addition, he made available an excellent and thorough set of lectures on heavy oil. These materials were important references for this report. Professor Dusseault gave permission to use many of the figures from his lectures in this report.

\section{About Argonne National Laboratory}

Argonne is a U.S. Department of Energy laboratory managed by UChicago Argonne, LLC under contract DE-AC02-06CH11357. The Laboratory's main facility is outside Chicago, at 9700 South Cass Avenue, Argonne, Illinois 60439. For information about Argonne, see www.anl.gov.

\section{Availability of This Report}

This report is available, at no cost, at http $/$ /www.osti.gov/bridge. It is also available on paper to the U.S. Department of Energy and its contractors, for a processing fee, from:

\author{
U.S. Department of Energy \\ Office of Scientific and Technical Information \\ P.O. Box 62 \\ Oak Ridge, TN 37831-0062 \\ phone (865) 576-8401 \\ fax (865) $576-5728$ \\ reports@adonis.osti.gov
}

\begin{abstract}
Disclaimer
This report was prepared as an account of work sponsored by an agency of the United States Government. Neither the United States Government nor any agency thereot, nor UChicago Argonne, LLC, nor any of their employees or officers, makes any warranty, express or implied, or assumes any legal liability or responsibility for the accuracy, completeness, or usefulness of any information, apparatus, product, or process disclosed, or represents that its use would not infringe privately owned rights. Reference herein to any specific commercial product, process, or service by trade name, trademark, manufacturer, or otherwise, does not necessarily constitute or imply its endorsement, recommendation, or favoring by the United States Government or any agency thereof. The views and opinions of document authors expressed herein do not necessarily state or reflect those of the United States Government or any agency thereof, Argonne National Laboratory, or UChicago Argonne, LLC
\end{abstract}




\section{Water Issues Associated with Heavy Oil Production}

prepared for

U.S. Department of Energy, National Energy Technology Laboratory

prepared by

J.A. Veil and J.J. Quinn

Environmental Science Division, Argonne National Laboratory

November 2008 
Page intentionally left blank. 


\section{Table of Contents}

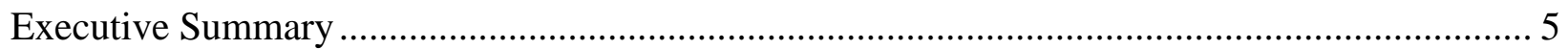

Chapter 1 - Introduction ...................................................................................................... 9

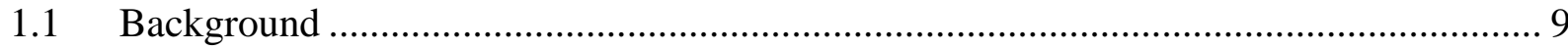

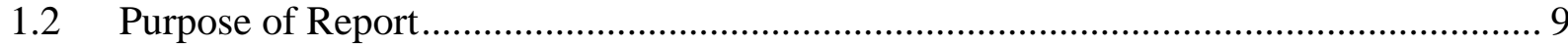

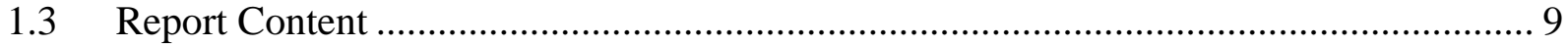

Chapter 2 - Heavy Oil Characteristics and Resources ................................................................ 11

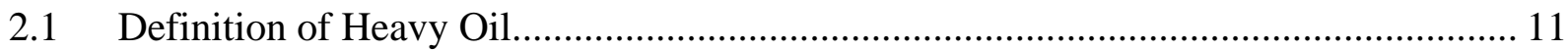

2.2 Types and Significant Deposits of Heavy Oil.............................................................. 12

2.2.1 Viscous Heavy Oil ............................................................................................ 12

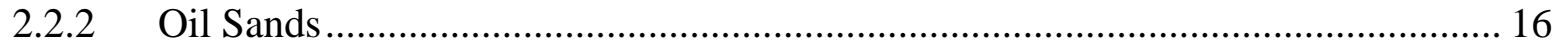

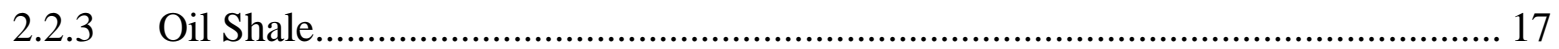

2.2.4 International Scope of Heavy Oil Activities ..................................................... 20

Chapter 3 - Heavy Oil Production Technologies ................................................................... 23

3.1 Technologies for Producing Viscous Heavy Oil and Oil Sands .................................... 23

3.1.1 Mining for Oil Sands ........................................................................................... 23

3.1.2 In Situ Technologies for Producing Viscous Heavy Oil and Oil Sands .................. 23

3.2 Technologies for Producing Oil Shale ……………….................................................. 38

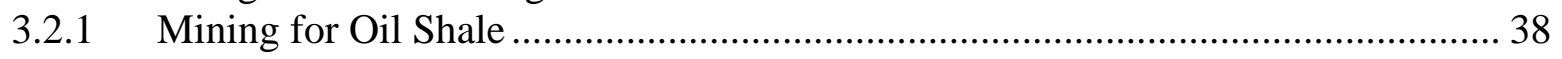

3.2.2 In Situ Technologies for Producing Oil Shale ...................................................... 40

3.2.3 Retorting and Upgrading.............................................................................................. 42

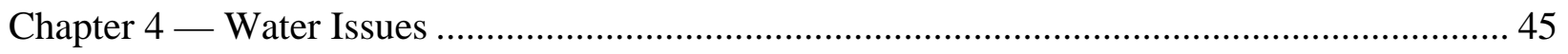

4.1 Water Usage in Heavy Oil Production ............................................................................ 45

4.1.1 Conversion of Volume Units ........................................................................... 45

4.1.2 Non-Process Water Uses.............................................................................. 45

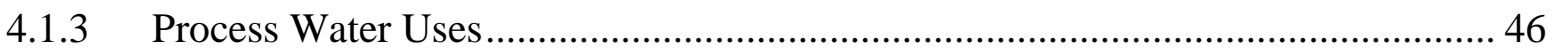

4.1.4 Dewatering Issues ................................................................................................ 47

4.2 Water Quantity Needs for Heavy Oil Production ............................................................ 47

4.2.1 Water Needs for Viscous Oil and Oil Sands Production .......................................... 47

4.2.2 Water Needs for Oil Shale Production................................................................... 48

4.3 Water Quality Concerns from Heavy Oil Production ...................................................... 50

4.3.1 Groundwater Quality Concerns ……………………………………………... 51

4.3.2 Surface Water Quality Concerns …………………………………………......... 52

4.3.3 Surface Water/Groundwater Interactions ……………........................................ 53

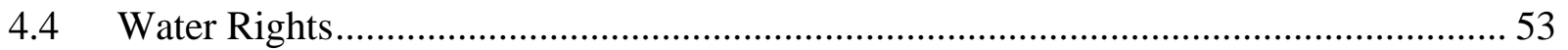

4.5 Water Regulatory Programs …………………………………………………….... 54

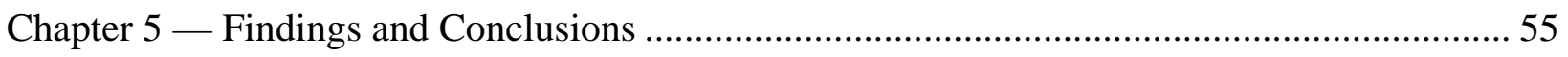

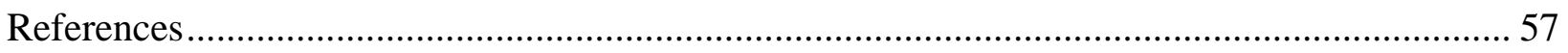




\section{List of Figures}

Figure 1. Map of Kern River Oil Field in California........................................................... 14

Figure 2. Map of Venezuela showing major heavy oil fields .............................................. 14

Figure 3. Location of Canadian oil sands and viscous heavy oil deposits............................... 15

Figure 4. Map of North Slope oil and gas fields showing location of heavy oil zone................ 16

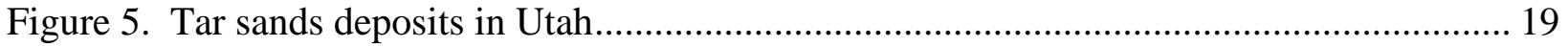

Figure 6. Oil shale deposits in Colorado, Utah, and Wyoming ............................................ 21

Figure 7. Well configuration for heavy oil field in Venezuela ............................................... 24

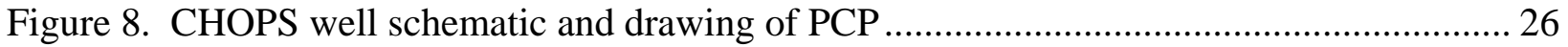

Figure 9. Production before and after initiation of CHOPS in Luseland Field........................... 27

Figure 10. Schematic drawing of VAPEX process................................................................ 28

Figure 11. Cross-section of formation showing IGI operations ............................................. 30

Figure 12. Lab test showing oil movement with and without pulsing.................................... 30

Figure 13. Field production results from 36 wells before, during, and after pulsing ................ 31

Figure 14. Relationship between temperature and viscosity in heavy oil................................ 31

Figure 15. Diagram showing a steam flood operation ....................................................... 32

Figure 16. Steam flooding operations in Wilmington Field, California ................................... 33

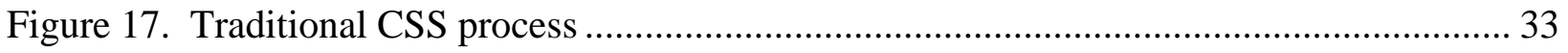

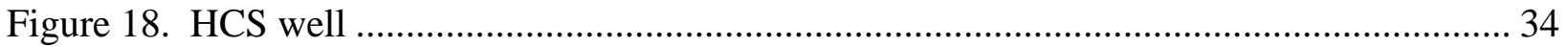

Figure 19. Schematic drawing of dual wells in SAGD operation........................................... 35

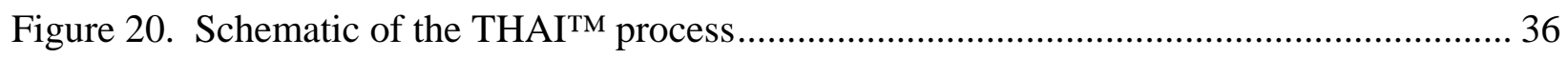

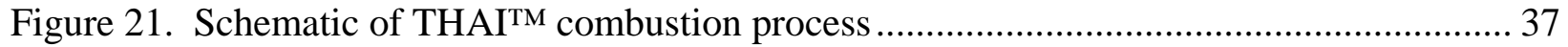

Figure 22. Generalized processes for conversion of oil shale to fuels and by-products.............. 39

\section{List of Tables}

Table 1. Water Requirements for Different Types of Oil Shale Plants ................................... 49

Table 2. Comparison of Water Requirements Estimated by Different Authors ........................ 50 


\section{Executive Summary}

Oil and gas companies are actively looking toward heavier crude oil sources to help meet demands and to take advantage of large heavy oil reserves located in North and South America. Heavy oil includes very viscous oil resources like those found in some fields in California and Venezuela, oil shale, and tar sands (called oil sands in Canada).

Many technologies are available to produce heavy oil. The technologies differ in several important ways: mining vs. in situ processes; cold (ambient temperature) vs. thermal processes; and technologies already in common use vs. emerging technologies. Examples of cold production processes for viscous heavy oil and oil sands include:

- Conventional production,

- Water flooding,

- $\quad$ Cold heavy oil production with sand (CHOPS),

- $\quad$ Solvent injection,

- $\quad$ Water injection alternating with gas injection (WAG),

- $\quad$ Inert gas injection, and

- $\quad$ Pressure pulsing.

Examples of thermal production processes for viscous heavy oil and oil sands include:

- $\quad$ Steam flooding,

- $\quad$ Cyclic steam stimulation (CSS),

- $\quad$ Steam assisted gravity drainage (SAGD), and

- Underground combustion.

Oil shale is produced using somewhat different methods. Oil shale can be mined in surface or underground mines or it can be produced by heating the deposits in place (in situ production). Steam or electromagnetic heating is generally used for in situ heating of oil shale.

The processes involved with heavy oil production often require external water supplies for steam generation, washing, and other steps. While some heavy oil processes generate produced water, others generate different types of industrial wastewater. Management and disposition of the wastewater presents challenges and costs for the operators. This report describes water requirements relating to heavy oil production and potential sources for that water. The report also describes how water is used and the resulting water quality impacts associated with heavy oil production.

In addition to requiring water, production of heavy oil requires a substantial amount of energy for removing the heavy oil from the ground, processing it, and transporting it off-site. Because of its higher viscosity, heavy oil presents more challenges for operators. 
Heavy oil production involves either mining large tracts of land, which results in surface disturbance, or drilling of numerous injection and recovery wells for in situ production. Both methods have the potential to cause impacts to ground and surface water resources. In addition, large-scale production of heavy oil resources will require local availability of large volumes of water to support the production process.

The heavy oil industry requires water for many non-process purposes that are applicable to nearly all production methods. Some of the uses directly support human needs, such as drinking water supply, toilets, showers, and laundries. Some of this water is needed at the job site, while other water is needed to support the living accommodations for the employees, presumably at an off-site but nearby location. Water is also needed to provide support and safety functions, such as dust control and fire protection water. If reclamation of the land surface is undertaken following the end of production, irrigation water may be necessary. To the extent that heavy oil production requires power generation from on-site or nearby facilities, large volumes of water may be needed to support the power plant. A new power plant or increased capacity at an existing plant would require water for steam generation, scrubber operations, cooling systems, and dust control.

Viscous heavy oil is produced via in situ processes. Steam is used to lower the viscosity of heavy oil, and water can be used to move heavy oil. Water may also be needed for hydrofracturing the formation to promote better fluid movement. Water is needed for steam production for steam flooding, CSS, and SAGD. Other water is used for water flooding and for WAG processes. Water may also be necessary to cool machinery used at the surface.

Much of the water used in these "wet" processes is recaptured along with the produced heavy oil. This "used" or "produced" water contains various contaminants that may interfere with subsequent reuse. Generally, some form of treatment is required prior to reuse. A "dry" combustion process may generate surplus water originating as formation water or as a product of combustion.

When oil sands are produced through an in situ process, water is used in the same ways described above. Some oil sands are mined, however. Because of their limited strength and stability, oil sands are generally mined through surface mines only. Water uses for a surface mine with surface retort could include:

- Water for mining and drilling operations,

- $\quad$ Cooling of equipment,

- $\quad$ Transport of ore and spent material, including the option of hydrotransport of tar sand slurry,

- $\quad$ Dust control for surface mines, crushers, overburden and source rock storage piles, and retort ash piles,

- $\quad$ Cooling of spent material exiting the retort, and

- Wetting of spent material prior to disposal. 
Oil shale mining may take place in surface mines or underground mines. Water uses for a surface or underground mine with surface retort are similar to those described in the previous section for oil sands mining.

For in situ projects, water may be needed for:
- Hydrofracturing,
- $\quad$ Steam generation,
- Water flooding,
- $\quad$ Quenching of kerogen products at producer holes,
- $\quad$ Cooling of productive zones in the subsurface,
- $\quad$ Cooling of equipment, and
- $\quad$ Rinsing of oil shale after the extraction cycle.

Depending on the quality of the shale oil produced directly from in situ processes, water may be required for additional processing of the product at the surface.

A large amount of water is required during the operations phase. The literature provides some actual examples of water use, but most of the volume estimates are projections. They are generic estimates that will vary based on site-specific factors. The proposed Colorado-Utah-Wyoming oil shale operations are estimated to require 2.6 to $4.0 \mathrm{bbl}$ of water for each barrel of shale oil produced from a surface or subsurface mine with surface retort.

Heavy oil production creates significant disturbances or disruptions of underground formations, groundwater hydrology, and land surface. Consequently, it affects the quality of ground and surface water resources at the production location and often in adjacent areas, too. The combination of geographic location, hydrologic setting, heavy oil type, the extraction technology used, and production rates contribute to the types, severity, and duration of impacts.

Surface water impacts can result from several aspects of oil shale and oil sands development. The need for large volumes of water is likely to draw down local stream levels such that aquatic habitats may be diminished. Stormwater runoff from disturbed surface areas at mines, spent shale and oil sands piles, access roads, and supporting facilities will carry contaminants into surface waters. Various construction activities (e.g., access roads, building construction, spoil disposal piles, mining or other recovery operations, power line construction) would expose fresh soil to intensified surface runoff caused by precipitation, as well as to wind erosion, leading to increases in sediment and salt contributions to streams. Processing of oil sands from mining operations uses a great deal of water and generates large volumes of wastewater. 
Page intentionally left blank. 


\section{Chapter 1 - Introduction}

\subsection{Background}

Crude oil occurs in many different forms throughout the world. An important characteristic of crude oil that affects the ease with which it can be produced is its density and viscosity. Lighter crude oil typically can be produced more easily and at lower cost than heavier crude oil. Historically, much of the nation's oil supply came from domestic or international light or medium crude oil sources. California's extensive heavy oil production for more than a century is a notable exception. Oil and gas companies are actively looking toward heavier crude oil sources to help meet demands and to take advantage of large heavy oil reserves located in North and South America.

Heavy oil includes very viscous oil resources like those found in some fields in California and Venezuela, oil shale, and tar sands (called oil sands in Canada). These are described in more detail in the next chapter.

\subsection{Purpose of Report}

Water is integrally associated with conventional oil production. Produced water is the largest byproduct associated with oil production. The cost of managing large volumes of produced water is an important component of the overall cost of producing oil. Most mature oil fields rely on injected water to maintain formation pressure during production.

The processes involved with heavy oil production often require external water supplies for steam generation, washing, and other steps. While some heavy oil processes generate produced water, others generate different types of industrial wastewater. Management and disposition of the wastewater presents challenges and costs for the operators.

This report describes water requirements relating to heavy oil production and potential sources for that water. The report also describes how water is used and the resulting water quality impacts associated with heavy oil production.

\subsection{Report Content}

Chapter 2 defines and describes heavy oil resources. It gives an indication of where significant U.S. and international deposits are located and the magnitude of those resources.

Chapter 3 offers short descriptions of various technologies used to produce heavy oil. Different technologies apply to different forms of heavy oil and to different geographic locations.

Chapter 4 discusses the water needs for operating different technologies, how water is used in heavy oil processes, and the potential surface water and groundwater quality impacts resulting from heavy oil production. 
Page intentionally left blank. 


\section{Chapter 2 - Heavy Oil Characteristics and Resources}

\subsection{Definition of Heavy Oil}

Heavy oil is generally defined using API gravity and may also include viscosity in the definition. API gravity was established as a uniform way of characterizing the density or specific gravity of oil by the American Petroleum Institute. API gravity is an arbitrary scale expressing the gravity or density of liquid petroleum products. The measuring scale is calibrated in terms of degrees API. It is calculated as follows:

API Gravity $\left(^{\circ}\right)=\left(141.5 \div\right.$ specific gravity of the oil at $\left.60^{\circ} \mathrm{F}\right)-131.5$

Higher API gravity ratings reflect lighter types of crude oil. The boundaries between different classes of oil (e.g., light, intermediate, heavy, extra heavy) all follow the same trend, but different authors choose slightly different boundaries between categories. Several examples are listed below.

DOE's Energy Information Administration (EIA) Petroleum Navigator tool on the EIA website ${ }^{1}$ offers the following definitions:

- $\quad$ Light crude has a gravity of greater than $38^{\circ}$ API.

- $\quad$ Intermediate crude ranges from $22^{\circ}-38^{\circ} \mathrm{API}$.

- Heavy crude has a gravity of less than $22^{\circ}$ API.

The U.S. Geological Survey (USGS) also considers the viscosity of the oil and provides the following definitions in Meyer and Attanasi (2003).

- $\quad$ "Light oil, also called conventional oil, has an API gravity of at least $22^{\circ}$ and a viscosity less than 100 centipoise (cP).

- $\quad$ Heavy oil is an asphaltic, dense (low API gravity), and viscous oil that is chemically characterized by its content of asphaltenes (very large molecules incorporating most of the sulfur and perhaps 90 percent of the metals in the oil). Although variously defined, the upper limit for heavy oil has been set at $22^{\circ} \mathrm{API}$ gravity and a viscosity of $100 \mathrm{cP}$.

- $\quad$ Extra-heavy oil is that portion of heavy oil having an API gravity of less than $10^{\circ}$.

- $\quad$ Natural bitumen, also called tar sands or oil sands, shares the attributes of heavy oil but is yet more dense and viscous. Natural bitumen is oil having a viscosity greater than $10,000 \mathrm{cP} . ”$

According to the Canadian Centre for Energy Information, ${ }^{2}$ the Canadian industry defines terms as follows:

\footnotetext{
${ }^{1}$ EIA defines API gravity at http://tonto.eia.doe.gov/dnav/pet/TblDefs/pet_pri_wco_tbldef2.asp. Accessed July 23, 2008.
} 
- $\quad$ Light crude oil has API gravity higher than $31.1^{\circ}$.

- $\quad$ Medium oil has API gravity between $31.1^{\circ}$ and $22.3^{\circ}$.

- Heavy oil has API gravity between $22.3^{\circ}$ and $10^{\circ}$.

- $\quad$ Extra heavy oil (bitumen) has API gravity of less than $10^{\circ}$.

The Canadian Centre for Energy Information also notes that the Canadian government has only two classifications:

- $\quad$ Light oil has API gravity of greater than $25.7^{\circ}$.

- Heavy oil has API gravity of less than $25.7^{\circ}$.

Dusseault (2001) recommends that viscosity be measured in situ, and that heavy oil has viscosity greater than $100 \mathrm{cP}$. He further suggests that the definition for heavy oil could also be expressed in terms of produceability. Heavy oil should have some mobility under naturally existing conditions and can flow to wells and be produced economically. In contrast, extra heavy oils, oil sands, and bitumen typically have both low API gravity and high viscosity, such that they do not flow naturally. They are typically produced through thermal processes or solvent addition.

\subsection{Types and Significant Deposits of Heavy Oil}

The two main forms of heavy oil typically described in the literature are viscous heavy oil and oil sands (bitumen). While some examples of each are clearly distinct, there is a gradient in properties that blurs the boundary between viscous crude found in a sandstone formation and oil sands. Several examples of each are described below.

Conspicuously absent from most of the heavy oil literature is oil shale. Oil shale in its natural state contains kerogen, a precursor to petroleum. Kerogen is the solid, insoluble, organic material in the shale that can be converted to oil and other petroleum products by pyrolysis and distillation. The kerogen in oil shale does not flow naturally and must be subjected to heat treatment to be released from the shale.

For the purposes of this report, oil shale is considered as a form of heavy oil. It faces many of the same water issues as oil sands. It is a very large potential hydrocarbon resource for the United States.

\subsubsection{Viscous Heavy Oil}

The first type of heavy oil described here is liquid or semi-liquid but is very viscous. In many parts of the world, heavy oil seeps to the surface and accumulates in pits or other depressions.

\subsubsection{California}

When Spanish explorers landed in California in the 1500s, they found Indians using asphaltum (very thick oil gathered from natural seeps) to make baskets and jars, to fasten arrowpoints to

\footnotetext{
${ }^{2}$ See

http://www.centreforenergy.com/generator2.asp?xml=/silos/ong/oilsands/oilsandsAndHeavyOilOverview01XML.as p\&template=1,1,1. Accessed July 23, 2008.
} 
shafts, and for ornaments. The explorers, in turn, used asphaltum to seal seams in their ships (Ritzius et al. 1993). The history of oil development in California is documented in Ritzius et al. (1993) and through an interesting website of the San Joaquin Geological Society. ${ }^{3}$ Another well known example of natural accumulations of viscous heavy oil in California is the La Brea tar pits located near Los Angeles.

California proved to have abundant oil reserves. By the late 1800s, oil was being produced through drilled wells. Exploration throughout the state found at least six giant oil fields, three of which contain heavy oil. The Midway-Sunset, Kern River, and South Belridge fields have produced more than 1 billion barrels of oil each (Curtis et al. 2002). DOE's EIA reports that California produced nearly 217 million bbl of crude oil in 2007. ${ }^{4}$ The EIA website does not differentiate between heavy oil and other forms of oil.

The Kern River field began production prior to 1900 and continues today (Figure 1). Curtis et al. (2002) report that the Kern River field has an API gravity of $10^{\circ}$ to $15^{\circ}$ and a viscosity of 500 to $10,000 \mathrm{cP}$. These features, along with the low initial reservoir temperature and pressure, led to a modest primary recovery. In the 1960s, the industry began trying steam injection to help the heavy oil flow more readily. Kern River crude oil reacted well to steam flooding, and the production rates increased substantially.

\subsubsection{Venezuela}

Venezuela is home to several large heavy oil fields (Figure 2). The western part of the country, around Lake Maracaibo, holds large reserves of heavy oil. The API gravity of the crude oil in the Maracaibo region ranges from $9^{\circ}$ to $33^{\circ}$ (Dusseault 2008a).

But the largest accumulation of extra heavy oil in the world is found in a zone in central Venezuela known as the Faja Petrolifera del Orinoco (often shortened to Faja del Orinoco or just Faja). Dusseault et al. (2008) note that the Faja is estimated to hold almost 1.3 trillion barrels of oil in place. The extra heavy crude oil here has a typical API gravity of $7^{\circ}$ to $10^{\circ}$. However, unlike many other low API-gravity crudes, the viscosity of Faja crude is somewhat lower, thereby allowing the crude to be partially produced without thermal techniques. Later technology advances have allowed greater production of the Faja.

\footnotetext{
${ }^{3}$ See http://www.geocities.com/mudsmeller/index.html. Accessed July 23, 2008.

${ }^{4}$ See http://tonto.eia.doe.gov/dnav/pet/pet_crd_crpdn_adc_mbbl_a.htm. Accessed September 5, 2008.
} 


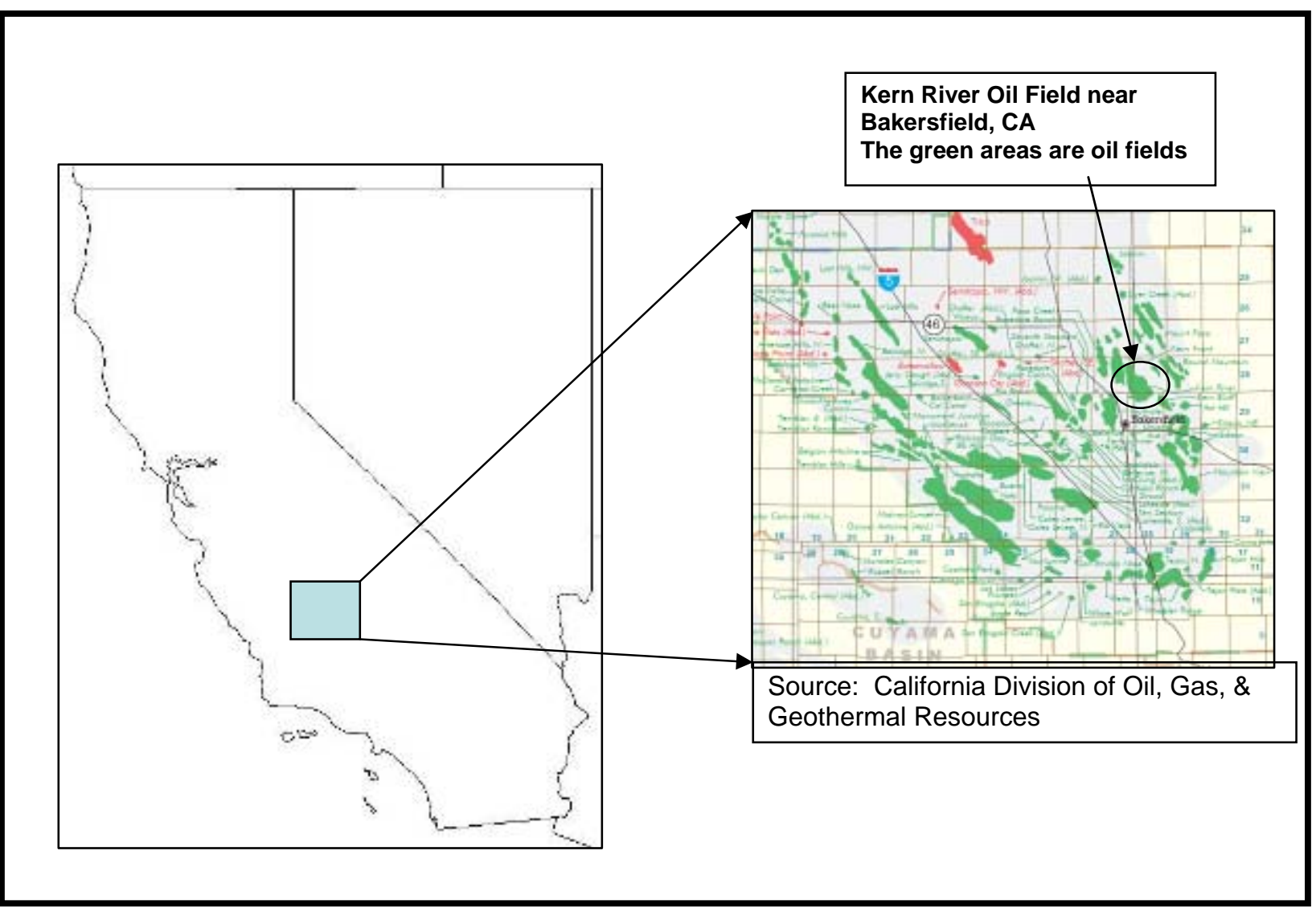

Figure 1. Map of Kern River Oil Field in California

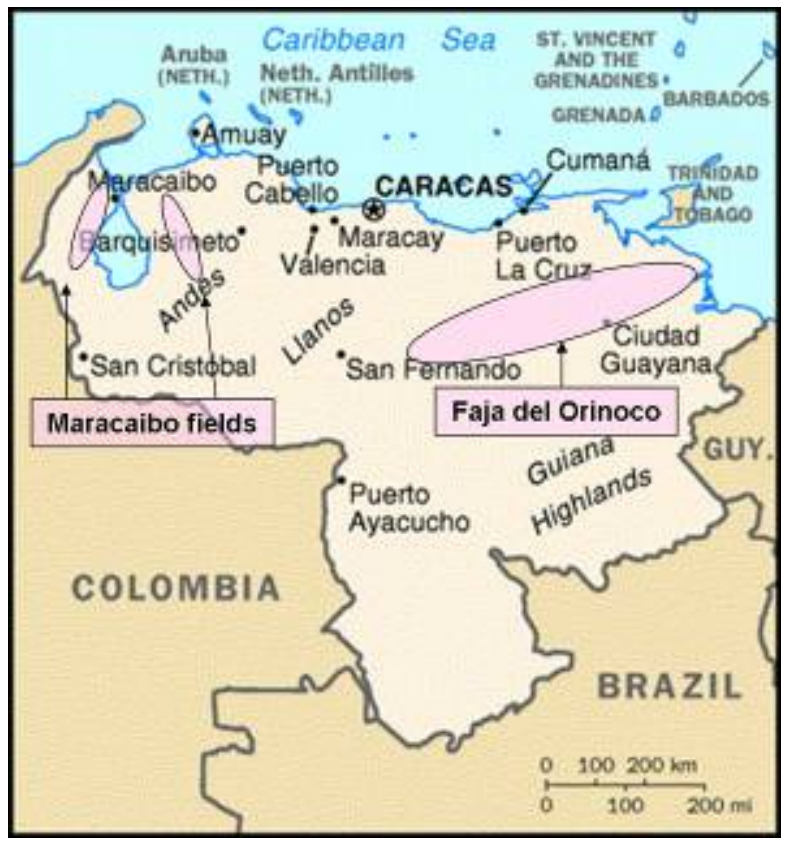

Figure 2. Map of Venezuela showing major heavy oil fields 


\subsubsection{Canada}

Canada is blessed with huge heavy oil resources in Alberta and Saskatchewan (Figure 3). The northern deposits are true tar sands (or oil sands) with combinations of extra-heavy crude oil and bitumen $\left(<10^{\circ} \mathrm{API}\right)$ of high viscosity $(>50,000 \mathrm{cP}$ in situ) filling the sandstone interstices. These are discussed in a later section. Other deposits can be considered as viscous heavy oil and are therefore mentioned here.

The more southerly and easterly deposits make up a large region of heavy oil deposits (known as the Heavy Oil Belt), found in a series of blanket sands and channel sands extending all the way from southwest Saskatchewan to zones overlying the Cold Lake Oil Sands near Bonnyville, (located about $120 \mathrm{~km}$ north of Lloydminster). The oil is considerably lighter in density ( $11^{\circ}$ to $18^{\circ}$ API gravity) and of much lower viscosity (500 to $20,000 \mathrm{cP}$ ) as compared to the major oil sands deposits to the north, therefore it is easier to produce, which is why it is the focus of much

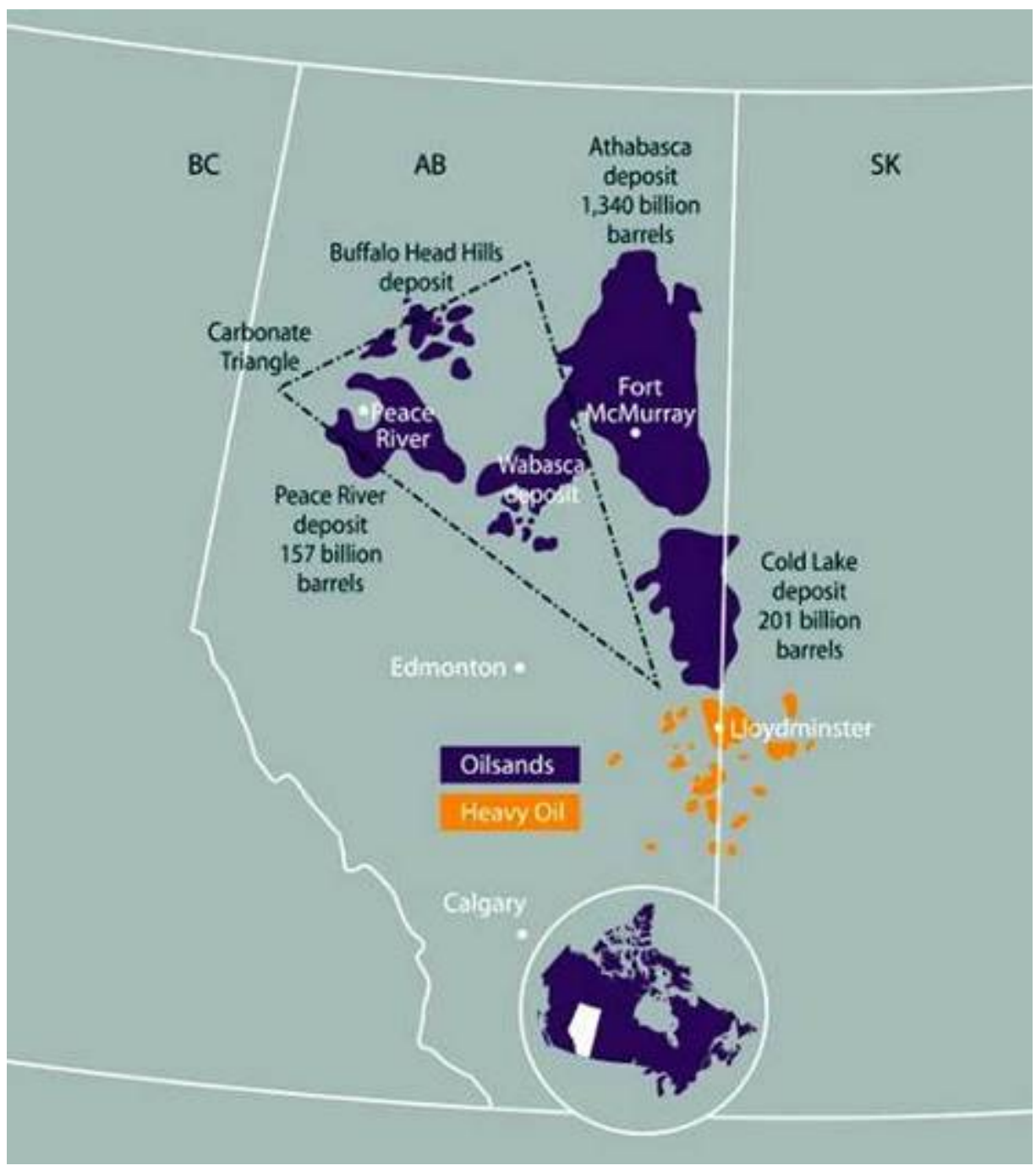

Figure 3. Location of Canadian oil sands and viscous heavy oil deposits (Source: CAPP website at http://www.canadasoilsands.ca/en/) 
of the recent increases in heavy oil production. There are perhaps 300 billion barrels of oil in place in the Heavy Oil Belt, and it is estimated that at least 50-60 billion barrels may ultimately be recoverable (Dusseault 2001).

\subsubsection{Alaska}

The North Slope of Alaska is home to two of the largest conventional oil fields in North America (Prudhoe Bay and Kuparuk — see Figure 4). Several other smaller oil fields that still would be considered giants by continental U.S. standards have been developed nearby. In addition to the more traditional North Slope oil formations, heavy oil formations overlie the main producing zones at Prudhoe Bay and Kuparuk. As much as 36 billion barrels of original-oil-in-place lie within the Ugnu, West Sak, and Schrader Bluff formations as heavy oil. That surpasses the original-oil-in-place of Prudhoe and Kuparuk combined (Mohanty 2004).

Located at a depth of 3,000 to 3,500 feet, these formations are extremely viscous. North Slope operators thus far have focused on the less-viscous crudes in the West Sak and Schrader Bluff heavy-oil formations, where viscosities range from 30 to 3,000 cP. Combined original-oil-inplace volumes for these two formations total about 10-20 billion barrels. The Ugnu formation has even higher viscosities.

\subsubsection{Oil Sands}

Oil sands (also referred to as tar sands in the United States) contain clay, sand, water, and bitumen. The bitumen in tar sands cannot be pumped from the ground in its natural state. Tar sands can be mined and processed to extract the oil-rich bitumen for subsequent refining. Bitumen can also be produced through in-situ underground heating or other recovery processes.

\subsubsection{Canada}

Canada has the world's second largest proven crude oil reserves (15\% of world reserves), after Saudi Arabia. Most of these vast reserves are in the form of oil sands located in Alberta. The oil sand resources are primarily located in four large deposits. Figure 1 shows the location of the major oil sands deposits as well as the viscous heavy oil deposits described above.

By far the largest and most accessible is the Athabasca Oil Sands, covering $40,000 \mathrm{~km}^{2}$. Located to the south of Fort McMurray, the formation probably contains one trillion barrels (bbl) of bitumen. The bitumen is highly viscous and is often of a specific gravity greater than water (API gravity less than $10^{\circ}$ ) (Dusseault 2001).

Some of the oil sands near Fort McMurray are close to the surface and can be mined. Up to 20\% of the total area can be developed using mining techniques. In situ techniques are needed for other deeper deposits (OSDC undated).

The Wabasca (or Wabiskaw) Oil Sands deposit lies above the western part of the Athabasca Oil Sands and extends westward. This area contains nearly 100 billion bbl of bitumen. The bitumen is highly viscous, similar to the Athabasca Oil Sands deposit. The depth of burial is $100 \mathrm{~m}$ to $700 \mathrm{~m}$ (Dusseault 2001). 
The Cold Lake Oil Sands are located about $20 \mathrm{~km}$ north of Bonnyville, Alberta. This deposit covers 22,000 $\mathrm{km}^{2}$ and probably contains more than 375 billion bbl of bitumen. The bitumen is highly viscous but considerably less so that the Athabasca oil sands, somewhat less sulphurous, and the depth of burial is $400 \mathrm{~m}$ to $600 \mathrm{~m}$ (Dusseault 2001). Presently, some of these deposits are being recovered using in situ technology (OSDC undated).

The Peace River Oil Sands are located west of the Athabasca and Wabasca deposits. This deposit probably contains nearly 200 billion bbl of bitumen. The bitumen is highly viscous, similar to the Athabasca deposit, and the depth of burial is 500 to $700 \mathrm{~m}$ (Dusseault 2001). These deep deposits are being recovered with in situ methods (OSDC undated).

\subsubsection{Venezuela}

Venezuela has vast heavy oil reserves. Some authors refer to the Venezuelan heavy oil as viscous heavy oil while others consider it to be oil sands. In this report, we treat the Venezuelan heavy oil as viscous heavy oil. The Venezuelan resources are described in Section 2.2.1.2.

\subsubsection{United States}

Although the U.S. oil sands reserves (typically called tar sands in the United States) are small compared to Canadian reserves, they still are sufficiently large to be an important source of oil. In the United States, tar sands resources are primarily concentrated in Eastern Utah, mostly on public lands. The in-place tar sands oil resources in Utah are estimated at 12 to 19 billion barrels (BLM 2008). Figure 5 shows the location of designated Special Tar Sands Areas in Eastern Utah.

\subsubsection{Oil Shale}

The discussion of oil shale resources in this section is taken from Veil and Puder (2006).

\subsubsection{United States}

A recent USGS report provides a very thorough review of worldwide oil shale resources (Dyni 2006). Oil shale occurs in at least 33 countries worldwide. The global oil shale resource base is believed to contain about 2.8 trillion barrels, of which the vast majority, about 2 trillion barrels, is located within the United States (including eastern and western shales). The most economically attractive deposits, containing an estimated 1.2 to 1.8 trillion barrels (with an oil content of more than 10 gallons/ton), are found in the Green River Formation of Colorado (Piceance Basin), Utah (Uinta Basin), and Wyoming (Green River and Washakie Basins) (DOE 2004). Figure 6 shows the location of these oil shale deposits. 


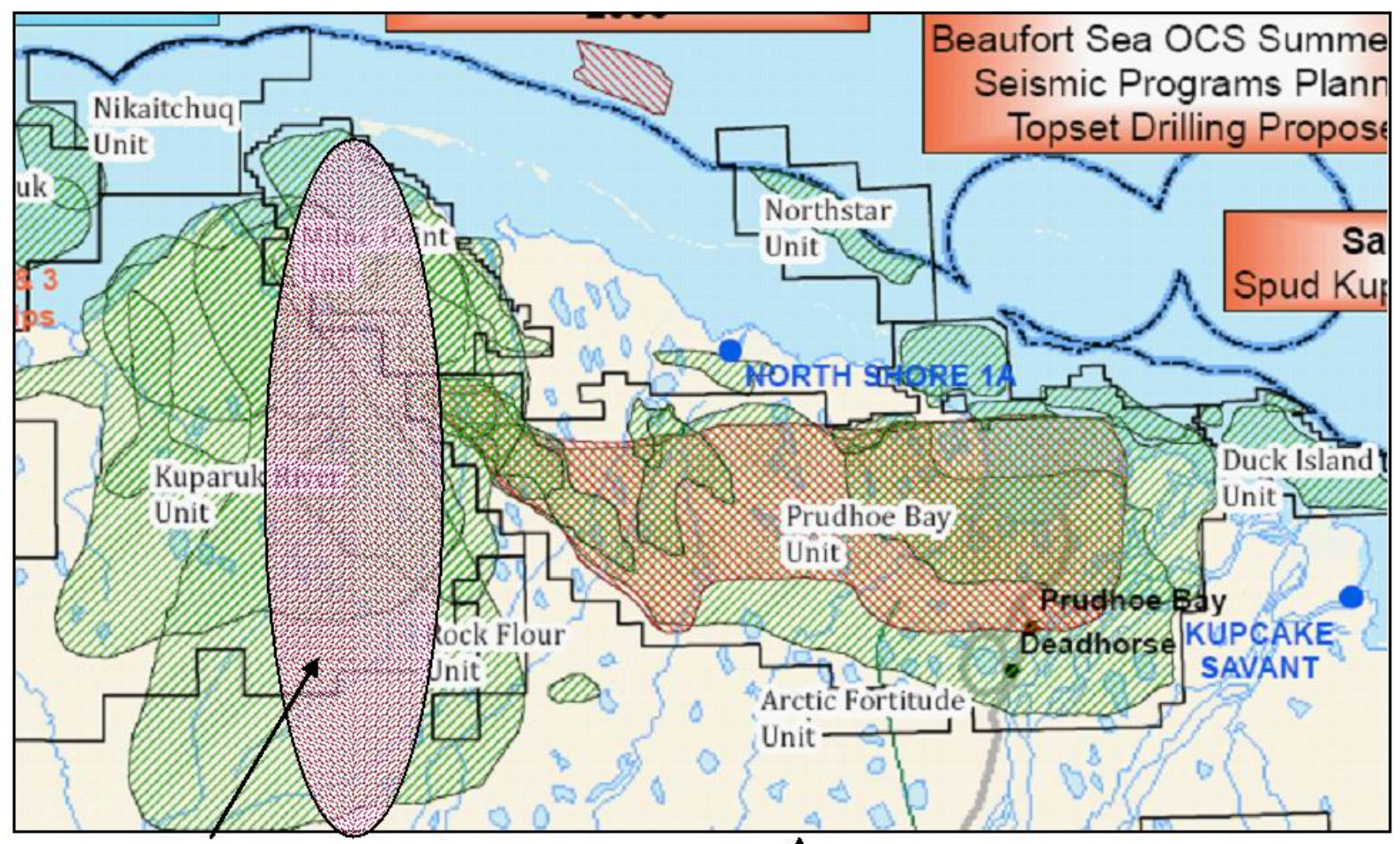

North Slope Heavy Oil Zones

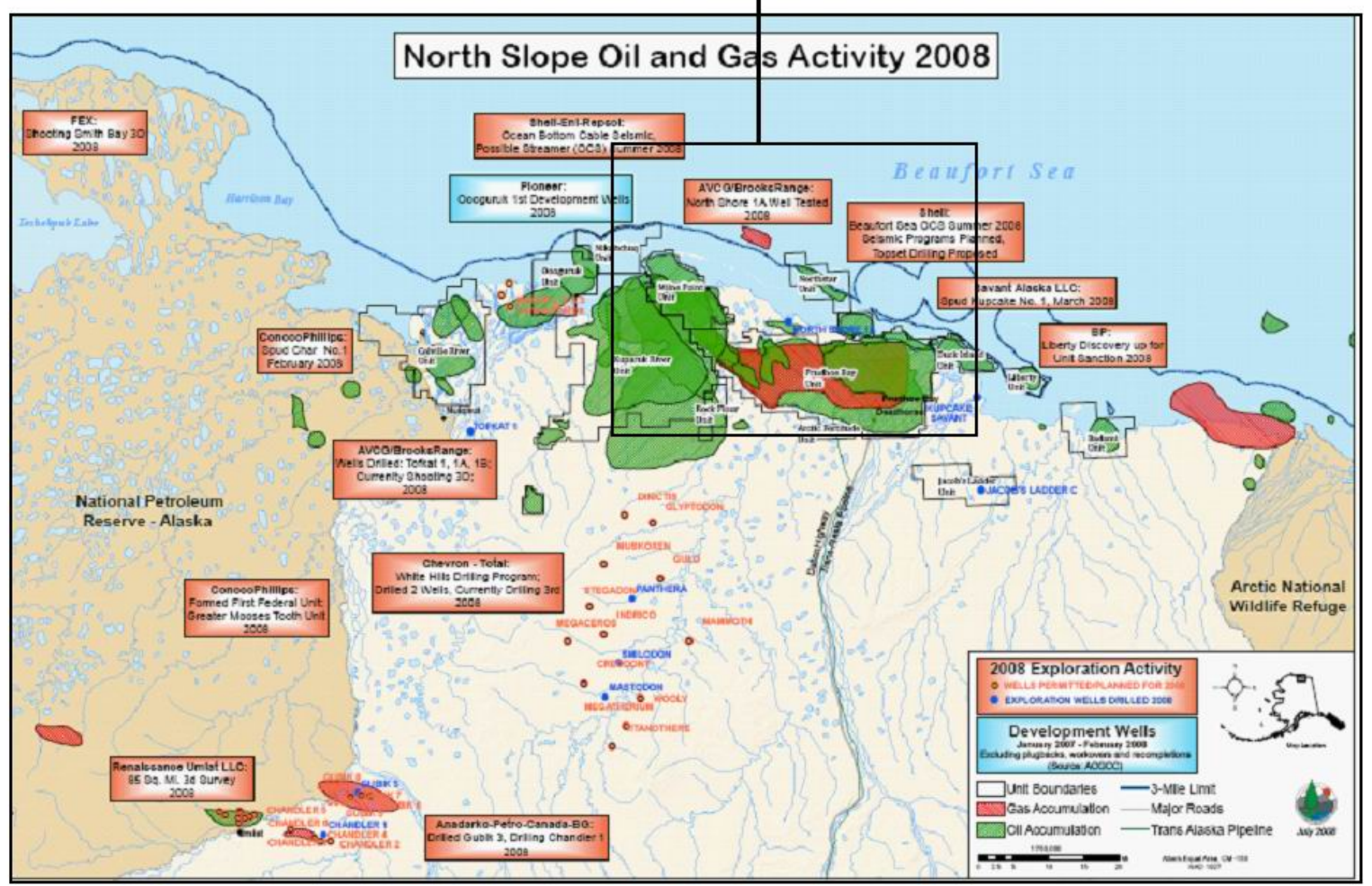

Figure 4. Map of North Slope oil and gas fields showing location of heavy oil zone (Source: Alaska Department of Natural Resources) 


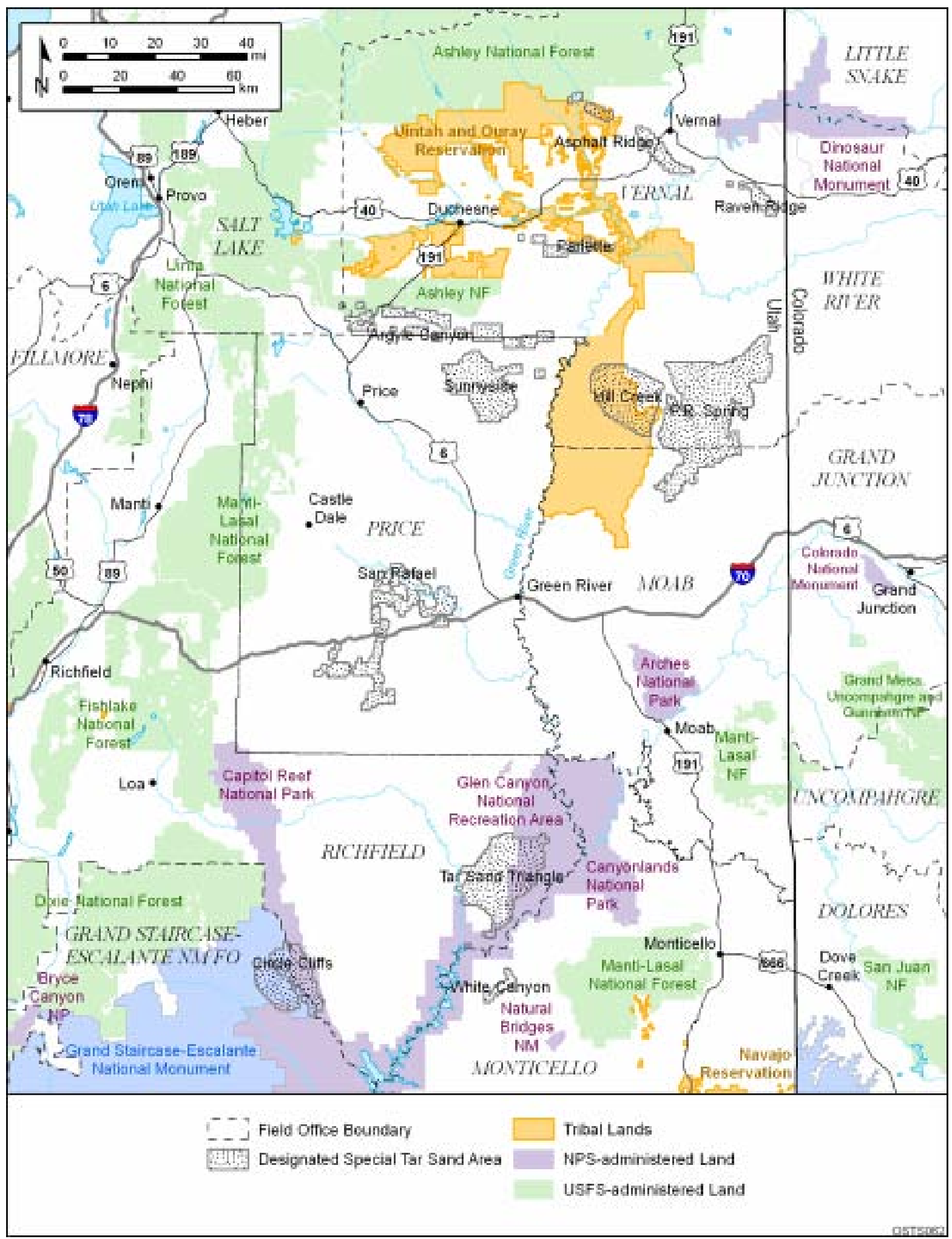

Figure 5. Tar sands deposits in Utah (Source: BLM 2008) 
Not all resources in place are recoverable. Nevertheless, the oil shale deposits of the Green River Formation have been extensively studied and overshadow all other deposits on the basis of both abundance and richness. More than $70 \%$ of the total oil shale acreage in the Green River Formation, including the richest and thickest oil shale deposits, is under federally owned and managed lands. Thus, the federal government directly controls access to the commercially attractive portions of the oil shale resource base.

Outside the Green River Formation, the Elko Formation of Nevada is another smaller but still attractive oil shale deposit. It contains in excess of 200 million barrels of fairly high-grade oil shale beds averaging at least 15 gallons/ton over a 15-foot thickness (RAND 2005). In the eastern United States, black, organic-rich shales, produced during the Devonian period, underlie portions of Kentucky, Indiana, Ohio, and Tennessee. However, when heated, the organic matter of the Devonian shales yields only about half as much oil as the organic matter in the Green River Formation shales. Because of considerations of grade, yield, and processing costs, eastern oil shale deposits are at present not likely candidates for development. However, other shale formations in the eastern United States, such as the Marcellus Shale, are being actively developed during 2008 for natural gas production.

\subsubsection{International Scope of Heavy Oil Activities}

In March 2008, representatives from many nations gathered in Edmonton, Alberta (Canada) for the World Heavy Oil Congress 2008. Technical papers were presented on many aspects of heavy oil production. The location of heavy oil production activities included many countries in addition to the well known heavy oil regions of Canada, Venezuela, and the United States. Some of the other countries with heavy oil resources include:

$$
\begin{array}{ll}
\text { - } & \text { China, } \\
\text { - } & \text { Egypt, } \\
\text { - } & \text { Iran, } \\
\text { - } & \text { Kazakhstan, } \\
\text { - } & \text { Kuwait, } \\
\text { - } & \text { Oman, and } \\
& \text { Turkey. }
\end{array}
$$

In addition to the World Heavy Oil Congress, other oil industry groups have shown interest in heavy oil. In October 2007, ConocoPhillips hosted a meeting of the Petroleum Environmental Research Forum (PERF) in Bartlesville, OK. The theme of the meeting was "Environmental Challenges of Heavy Crude Oils” focusing on industry applications for air, water, solids, and remediation. One of the conclusions from that meeting is that water is a major factor in current and future decisions regarding the development of heavy oil. 


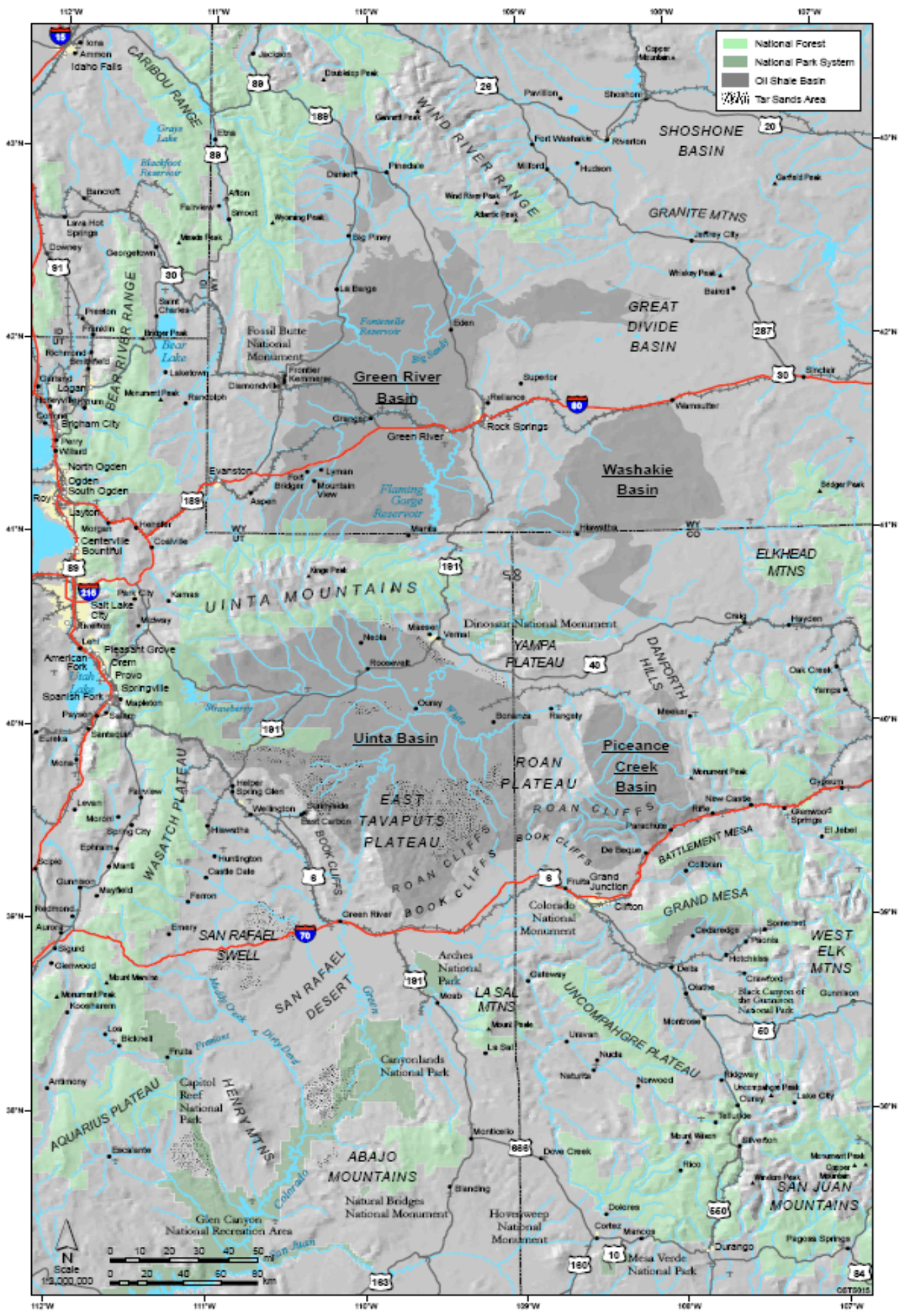

Figure 6. Oil shale deposits in Colorado, Utah, and Wyoming (Source: http://ostseis.anl.gov; oil shale basins defined by RAND 2005) 
Page intentionally left blank. 


\section{Chapter 3 - Heavy Oil Production Technologies}

Heavy oil deposits are found in many parts of the world in many different geological and climatic settings. These factors, along with the viscosity and API gravity of different heavy oil deposits, lead to a wide array of technologies for producing the oil. The technologies differ in several important ways:

- $\quad$ Mining vs. in situ processes,

- $\quad$ Cold (ambient temperature) vs. thermal processes,

- $\quad$ Technologies already in common use vs. emerging technologies.

The following sections include brief descriptions of the key technologies. Heavy viscous oil and oil sands share comparable technologies; these are described together. Some of the technologies employed to produce oil shale follow different processes; therefore, oil shale is included in a separate section.

\subsection{Technologies for Producing Viscous Heavy Oil and Oil Sands}

\subsubsection{Mining for Oil Sands}

When heavy oil deposits are located close to the surface, physical removal (open pit mining) may be a cost-effective technology. These systems use large hydraulic and electrically powered shovels to dig up tar sands and load them into enormous trucks that can carry up to 320 tons of tar sands per load. For example, the Syncrude and Suncor oil sands operations near Fort McMurray, Alberta, use the world's largest trucks and shovels to recover bitumen. The trucks haul the tar sands to crushers that break up lumps and remove rocks. Photos of the operations there can be found at http://ostseis.anl.gov/guide/photos/index.cfm.

\subsubsection{In Situ Technologies for Producing Viscous Heavy Oil and Oil Sands} Hart Energy (2006) provides a good overview of many different in situ technologies. Each technology is described below. To the extent possible, information is included on current technology usage as indicated by papers presented at the recent World Heavy Oil Congress 2008.

\subsubsection{Cold Production Technologies}

Cold production technologies do not use heating of the formation to reduce the viscosity of heavy oil to make it flow. Other approaches are employed as described below.

\subsection{Conventional Production}

In Venezuela, some of the heavy oil has low enough viscosity that it can be collected using networks of horizontal wells with multiple lateral branches (Hart Energy 2006). Curtis et al. (2002) report that initially the operators at the Zuata field drilled two horizontal wells into a series of "drainage rectangles" of $1,600 \mathrm{~m}$ by $600 \mathrm{~m}$ size. The results from the first 95 wells did not meet expectations, so the operator embarked on an extensive data acquisition program. The next wells were drilled with multiple laterals in various patterns. Curtis et al. (2002) shows figures of six different multilateral patterns used in the Faja region. The use of multilaterals and 
improved placement of well completions (resulting from the data collected) allowed the operator to achieve its target production of 120,000 bbl/day by 2001 .

At another Venezuela location, the Sincor project, the operator (Total) has used horizontal wells and progressing cavity pumps (PCPs) to produce heavy oil. Hart Energy (2006) reports that Total had reached a production level of $200,000 \mathrm{bbl} /$ day of heavy oil with $8^{\circ}$ to $8.5^{\circ}$ API gravity by 2004.

Dusseault (2008a) depicts the planned (top) and actual layout (bottom) of horizontal wells with many laterals to collect heavy oil in Venezuelan fields (Figure 7). The developers planned a straightforward symmetrical pattern of lateral wells. However, once the production started, the actual well geometry was much more intricate as shown in the bottom drawing on Figure 7.

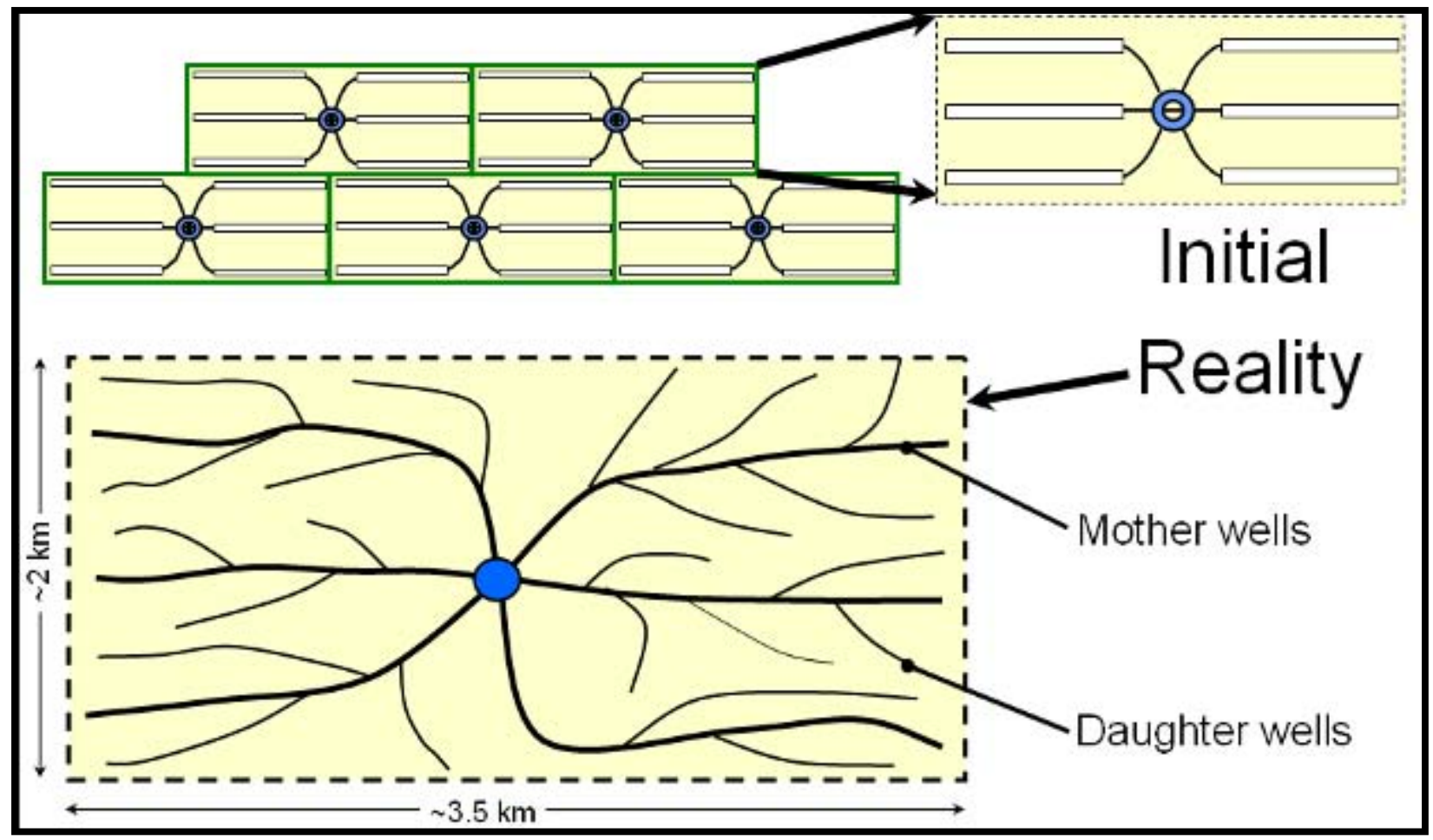

Figure 7. Well configuration for heavy oil field in Venezuela (Source: Dusseault 2008a)

\subsection{Water Flooding}

Water flooding has been used for decades to enhance recovery of conventional oil and to extend the life of producing reservoirs. In limited circumstances, water flooding can be employed in heavy oil deposits too. In a Canadian operation at Pelican Lake, EnCana uses a horizontal well water flood to produce heavy oil with $12^{\circ}$ to $15^{\circ} \mathrm{API}$ gravity. The water flood is aided by polymer addition (Hart Energy 2006).

Al-Sikaiti and Regtien (2008) report on water flooding in Oman. The region contains numerous heavy and viscous oil sandstone reservoirs located at a depth of approximately 1,000 $\mathrm{m}$. The reservoirs contain highly viscous (90-400 cp), medium density oil ( $18^{\circ}$ to $\left.22^{\circ} \mathrm{API}\right)$ with weak- 
to-strong aquifer support. The operator (Petroleum Development Oman [PDO]) implemented water flooding on some of the fields. The water injection rate increased from 95 million bbl/day in 2000 to about 285 million bbl/day in 2007. Currently, about $10 \%$ of the oil production is directly resulting from water flooding and this percentage will increase significantly in the next few years.

\subsection{CHOPS}

Cold Heavy Oil Production with Sand (CHOPS) is a production technique that operates contrary to the conventional wisdom that sand should be blocked from entering a well. Perhaps the most thorough discussion of CHOPS technology is found in Dusseault (2001). Readers are encouraged to consult that reference for much more detailed information on CHOPS.

CHOPS technology encourages production of sand from unconsolidated sandstone reservoirs. As the produced sand moves from the formation into the well, it leaves behind channels referred to as "wormholes." This increases permeability near the wellbore and allows more oil to reach the wellbore. Heavy oil production has increased 10- to 20-fold after converting wells from traditional production to CHOPS production (Hart Energy 2006).

CHOPS technology typically uses vertical wells fitted with PCPs to move the large volume of sand to the surface (Figure 8). PCPs are more effective for pumping the sand-laden material to the surface. PCPs typically include a stainless steel rotor mechanism that moves inside of an elastomer-lined helical cavity. Sand production initially can be as high as $40 \%$ by volume of the produced material. Later, the sand concentration drops but still remains high at $0.5 \%$ to $10 \%$ by volume (Dusseault 2001).

Dusseault (2008a) provides many examples of the dramatic increase in heavy oil production from individual wells in the Luseland and Edam fields in Saskatchewan that had been previously operated for primary production. For an example, see Figure 9. When the wells were converted to CHOPS configuration and operation, the oil production increased dramatically and resulted in large incremental production over the life of the well. Dusseault also notes that there are hundreds of CHOPS fields in the Heavy Oil Belt of Canada. In 2003, those wells contributed about 700,000 bbl/day of oil production. The oil had a viscosity range of 50-15,000 cP (most fields are $>1,000 \mathrm{cP}$ ). Wells were completed at depths from 360 to $900 \mathrm{~m}$ (Dusseault 2008a). Collins et al. (2008) report on the use of CHOPS in the Karazhanbas Field, a giant shallow heavy oil field in western Kazakhstan. The heavy oil deposit is less than $460 \mathrm{~m}$ deep and contains heavy oil ( $\sim 400 \mathrm{cP})$ in seven reservoir zones. PCPs are used to lift the oil, and sand is allowed to enter into perforated zones. Production of about 38,000 bbl/day was reached by January 2004, an increase of over 25,000 bbl/day within 4 years. Sand flux is far lower than in Canadian cases because of low oil viscosities. 


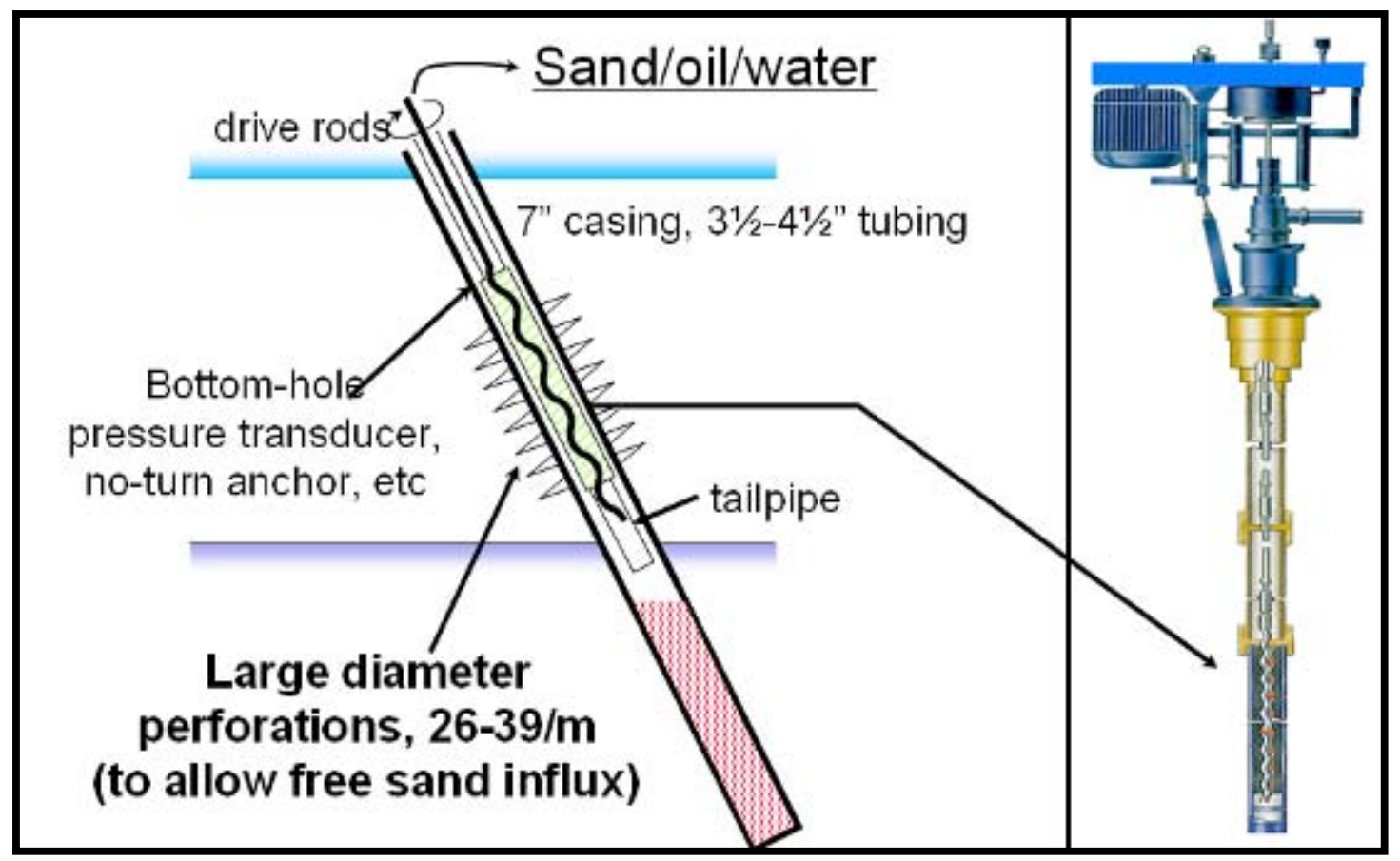

Figure 8. CHOPS well schematic and drawing of PCP (Source: Dusseault 2008a)

\subsection{Solvent Injection}

Rather than using steam to reduce the viscosity of heavy oil, solvent extraction technologies rely on injection of a solvent into the heavy oil deposit. In order for solvent extraction processes to be effective, the solvent must mix with and thin the heavy oil.

Kristoff et al. (2008) describe the Joint Implementation of Vapor Extraction (JIVE) research program for studying solvent vapor extraction (SVX) technology for recovering heavy oil reservoirs in western Canada. SVX entails injection of a gaseous solvent, typically propane, butane, or carbon dioxide, into a reservoir through either horizontal or vertical wells. The solvent dissolves into the oil (through diffusion/dispersion), reducing its viscosity enough to allow the oil to flow to a production well and be pumped to surface. Methane, used as an immiscible carrier gas for the solvent, may provide some pressure support to assist production.

Perhaps the most common solvent extraction technology is called vapor-assisted petroleum extraction (VAPEX). The VAPEX process involves continuous solvent injection through a horizontal well that is aligned with a horizontal production well located about three to five meters below it (Figure 10). SVX (a more generic term) includes all forms of cyclic and continuous injection schemes, well geometry (vertical and horizontal), and well placement (lateral or vertically separated — or both). JIVE includes solvent injection field pilots in three distinctly different reservoirs: Edam and Luseland in Saskatchewan, and Fort Kent in Alberta. More information on the three pilot studies, conducted by three heavy oil producers, are given in the following paragraphs (Kristoff et al. 2008). 


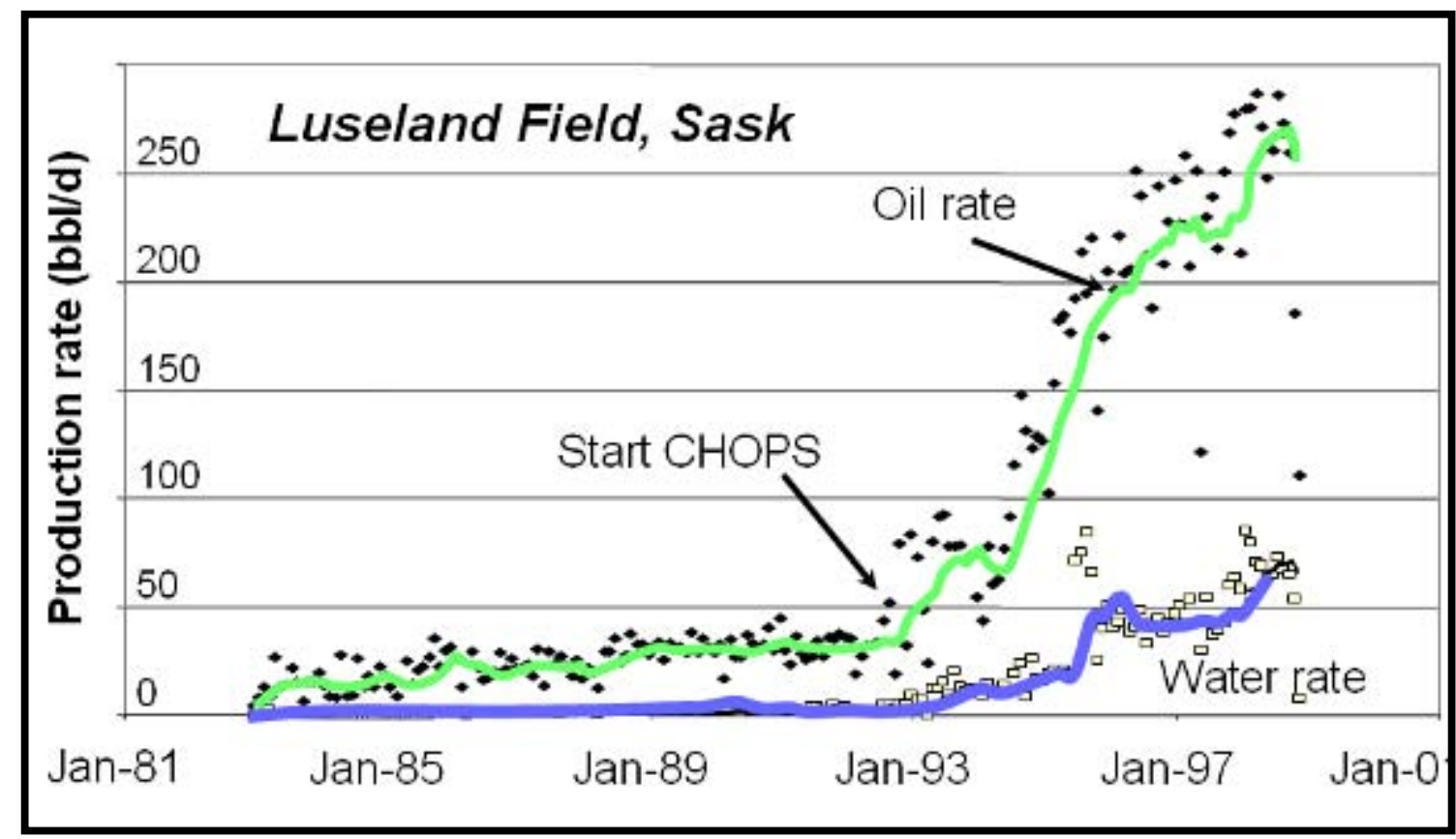

Figure 9. Production before and after initiation of CHOPS in Luseland Field (Source: Dusseault 2008a)

Husky Energy Inc. began solvent injection in June 2006 into two depleted wells in Edam field. It has since expanded to tie in two additional wells. Injection and production are cycled between two formations, both of which are unconsolidated sands. One of the formations contains $12^{\circ}$ API oil with a viscosity of $15,000 \mathrm{cP}$, and the other formation contains $11^{\circ}$ API oil with a viscosity of 27,000 cP. Husky is injecting a blend of purchased propane and methane. Results to date for both incremental oil recovery and viscosity reduction have been encouraging.

Nexen Inc. started a pilot test at Luseland in February 2007. Nexen is using a single-well cyclic solvent strategy. The oil quality ranges from $12.5^{\circ} \mathrm{API}$ and $3,500 \mathrm{cP}$ in the northwest, to $11.5^{\circ}$ API and 6,500 cP in the southwest portion of the field.

Canadian Natural Resources Limited (CNRL) will host the pilot study at Fort Kent. ${ }^{5}$ CNRL plans to inject a blend of methane and propane through vertical wells. A gravity drainage process is foreseen, whereby diluted oil will drain to the bottom of the pay zone and will be produced through a horizontal well. The Fort Kent oil has a gravity of $12^{\circ}$ API and viscosity ranging from 15,000 to $20,000 \mathrm{cP}$.

\footnotetext{
${ }^{5}$ At the time the Kristoff et al. paper was written (presumably early 2008 or late 2007), the CNRL pilot was not yet operating.
} 


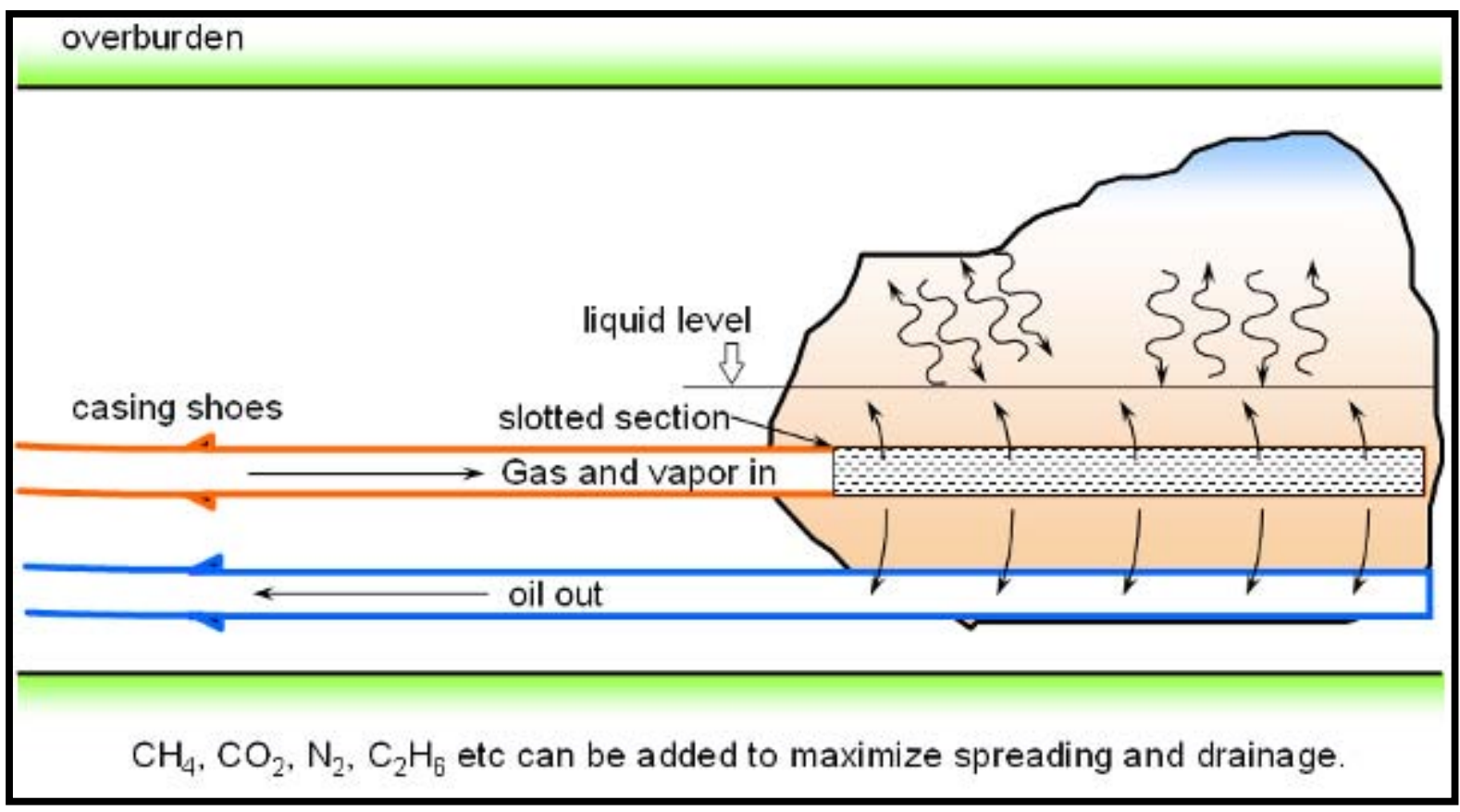

Figure 10. Schematic drawing of VAPEX process (Source: Dusseault 2008a)

\subsection{WAG}

Another method of enhancing heavy oil production is to use Water Alternating Gas (WAG). As the name implies, the technique alternates injection of a suitable gaseous solvent and water. The gas serves as a solvent to reduce the viscosity of the heavy oil while the water helps to push oil to the producing well. Although the technique has been used for decades to enhance recovery of light oil, little information could be found on actual field use of WAG for stimulating heavy oil production.

Mohanty (2004) conducted research to develop mathematical models to find optimum solvent, injection schedule, and well-architecture for a WAG process in a North Slope shallow sand viscous oil reservoir. Mohanty constructed a high-pressure "quarter 5-spot" model to evaluate the sweep efficiency of miscible WAG floods. WAG displacement reduces bypassing of oil-rich zones compared to gas floods and improves oil recovery in core samples tested in the laboratory. As the WAG ratio decreased and slug size increased, oil recovery increased. Oil was recovered faster with increased slug size and decreased WAG ratio in the simulations for field cases studied.

Cobanoglu (2001) describes a WAG feasibility study conducted for the Bati Kozluca field in Turkey. Oil gravity is $12.6^{\circ} \mathrm{API}$ with a very high viscosity of $500 \mathrm{cP}$ at reservoir conditions. The study predicts that more than 7 million bbl of incremental oil will be produced. The results indicate that production could be nearly doubled by instituting WAG (from $5.5 \%$ to $10.3 \%$ of original oil in place). 


\subsection{Inert Gas Injection}

Heavy oil can be forced downward in a formation by injection of gas into the top of the formation (inert gas injection or IGI). Examples of the gases used include nitrogen, carbon dioxide, methane, and flue gas (Dusseault 2008a). The gas is used to push the heavy oil downward. Methane can also be used as part of solvent extraction (see 3.1.2.1.4), although when that is the intent, the methane is injected into a horizontal well located just above and parallel to the producing well. In an IGI project, the methane is injected through a series of vertical wells near the top of the producing formation.

Dusseault (2001 and 2008b) describes IGI operational strategy. Gas is injected to create a gas/oil interface that is slowly displaced toward long horizontal production wells located near the bottom of the formation. It is essential to balance the injection and production volumes carefully so that the interface between the advancing gas phase and the receding oil phase is kept as close to horizontal as possible and "coning” of gas or water is avoided (Figure 11). The interfaces in IGI are gravity-stabilized because of the difference in phase densities, so that at slow drainage rates the interfaces remain approximately horizontal. During production, if the water cut increases, the production rate is reduced so that interface stability is recovered. Alternatively, if gas is injected too quickly, gas coning can develop, and if this is observed, the gas injection rate must be reduced to sustain stability. The process is continued until the oil zone is pushed down to the horizontal well, achieving the high oil recovery percentages possible with gravity drainage methods.

In reservoirs with excellent vertical permeability, the bottom water zone can also be injected with water to cause the oil-water interface to rise slowly toward the production well. As with all gravity drainage processes, if there is no bottom displacement, horizontal wells must be placed as low in the structure as possible because underlying oil will not be recovered (Dusseault 2001).

\subsection{Pressure Pulsing Technology}

Pressure Pulse Technology (PPT) is based on the discovery that large amplitude, low-frequency pulsing wave energy enhances flow rates in porous media (Dusseault 2001 and 2008b). PPT can reduce the rate of depletion, increase oil recovery percentage, and prolong the life of wells. Also, it has been found that very large amplitude pressure pulses applied for 5-30 hours to a blocked producing well can re-establish economic production in a CHOPS well for many months, possibly years. This approach is now widely used in Alberta and Saskatchewan to rehabilitate blocked CHOPS wells.

Dusseault (2008a) includes a photograph of two identical lab tests that pushed heavy oil through clear sand-packed test cells (Figure 12). The image on the left shows oil movement without pulsing, while the image on the right shows oil movement with pulsing. Clearly the oil moves more extensively through the test cell when pulsing is applied. 


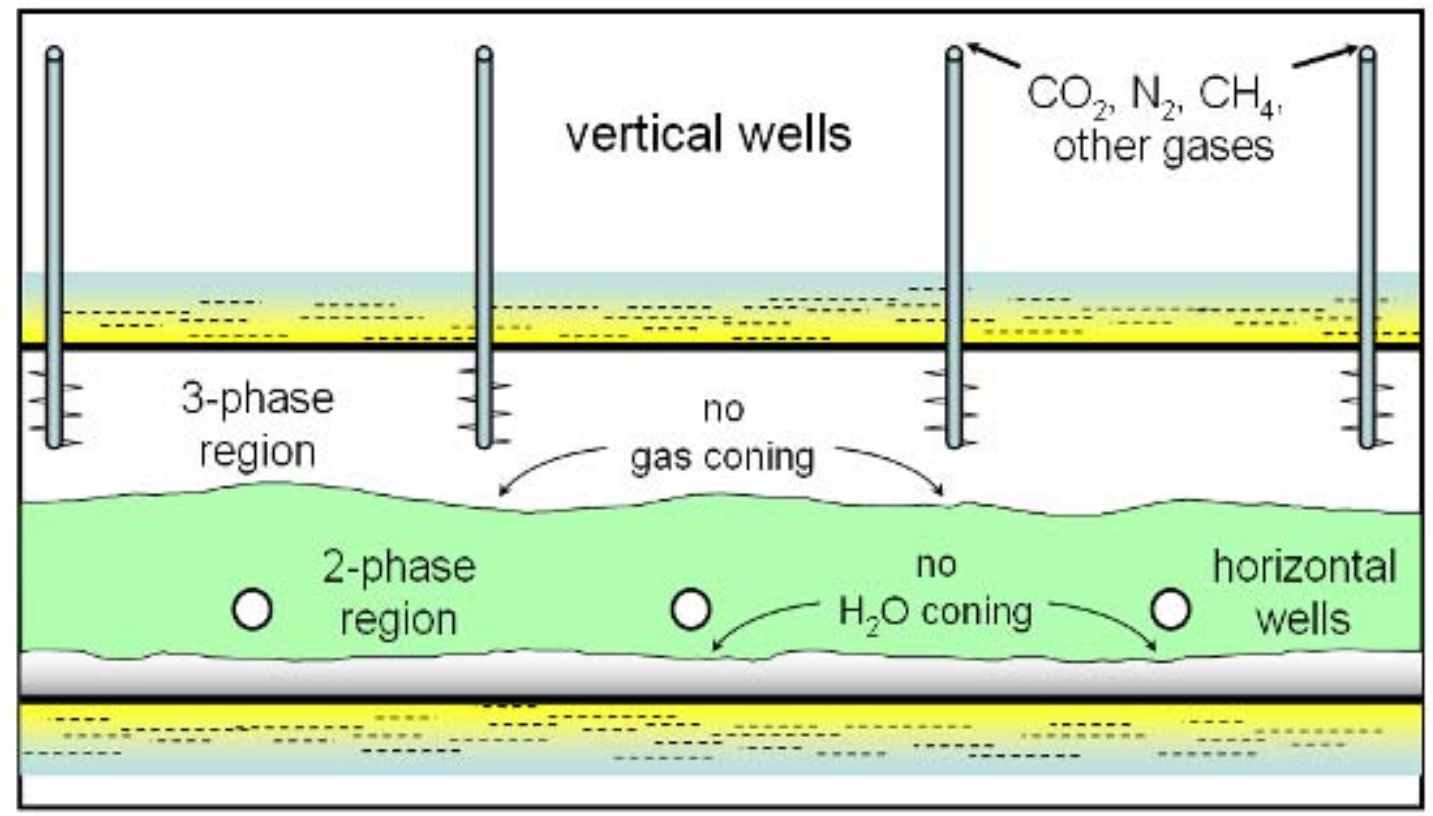

Figure 11. Cross-section of formation showing IGI operations (Source: Dusseault 2008a)

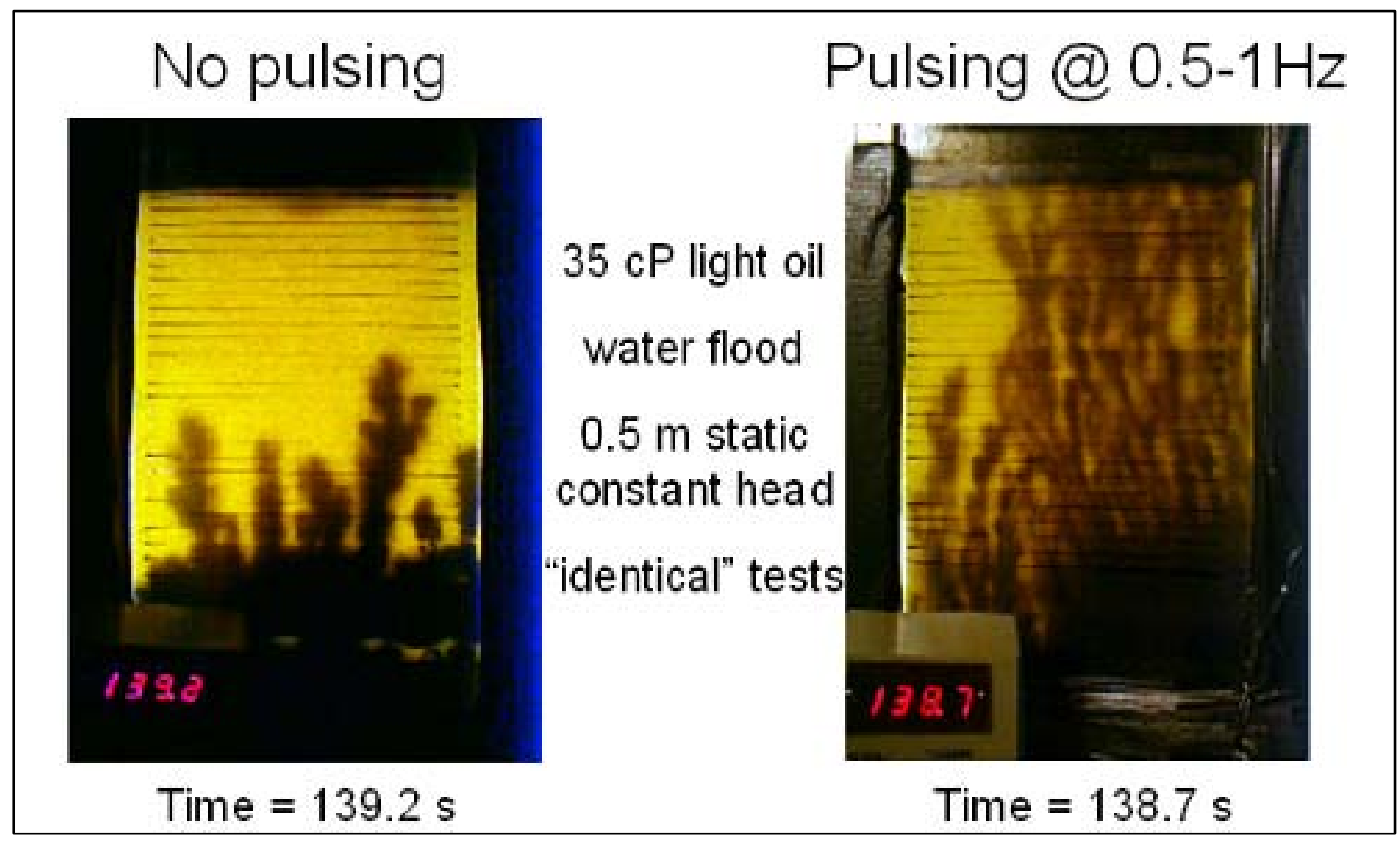

Figure 12. Lab test showing oil movement with and without pulsing (Source: Dusseault 2008a) 
Dusseault (2008a) also includes a figure depicting the results of a field trial of PPT in an unnamed location (Figure 13). Before pulsing was added, the daily oil production from the field was in steady decline. Upon starting pulsing, the oil production was fairly steady and continued at a similar rate even after pulsing was stopped.

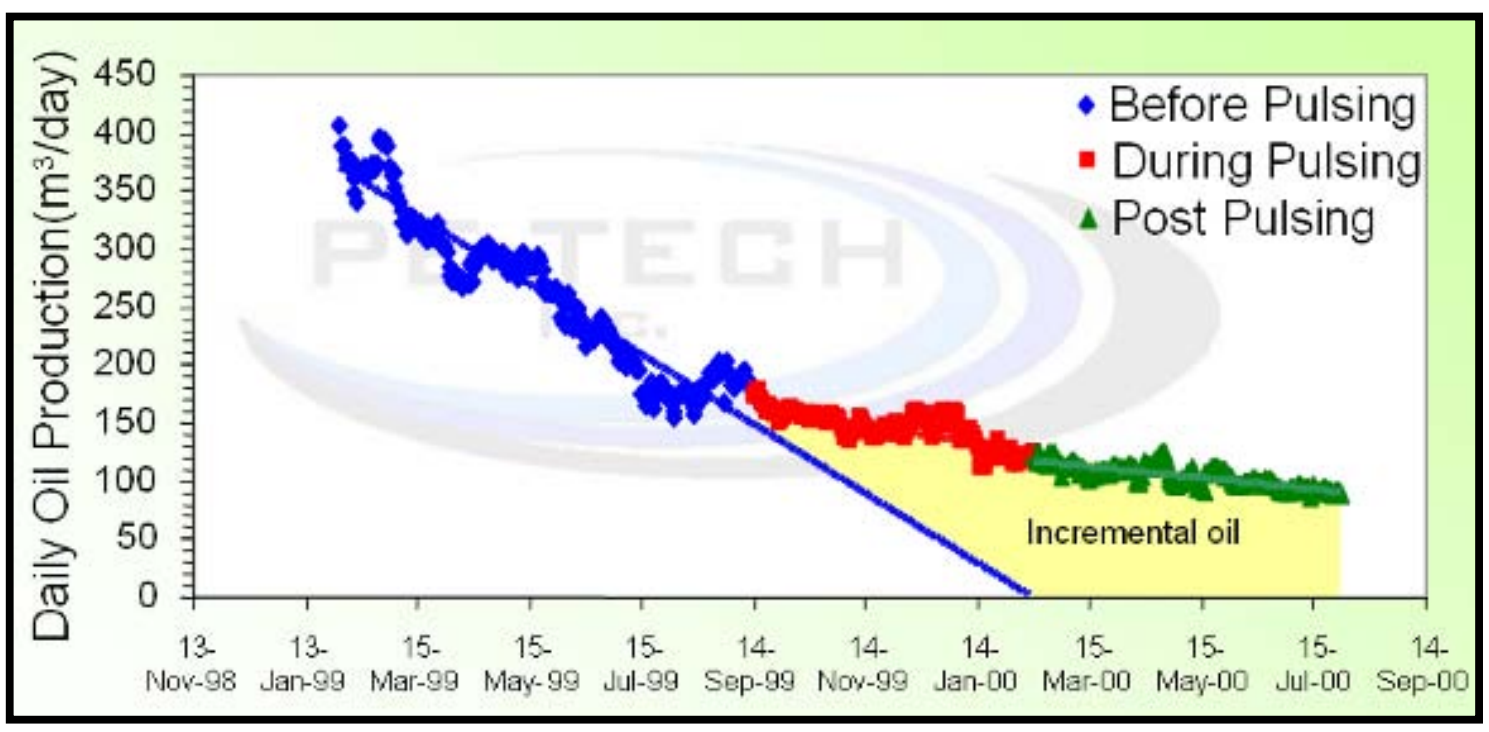

Figure 13. Field production results from 36 wells before, during, and after pulsing (Source: Dusseault 2008a)

\subsubsection{Thermal Technologies}

This section describes several technologies that rely on heating the heavy oil to reduce the viscosity of the oil and allow it to flow more readily to a production well. Figure 14 (from Dusseault 2008a) shows how viscosity declines as temperature rises.

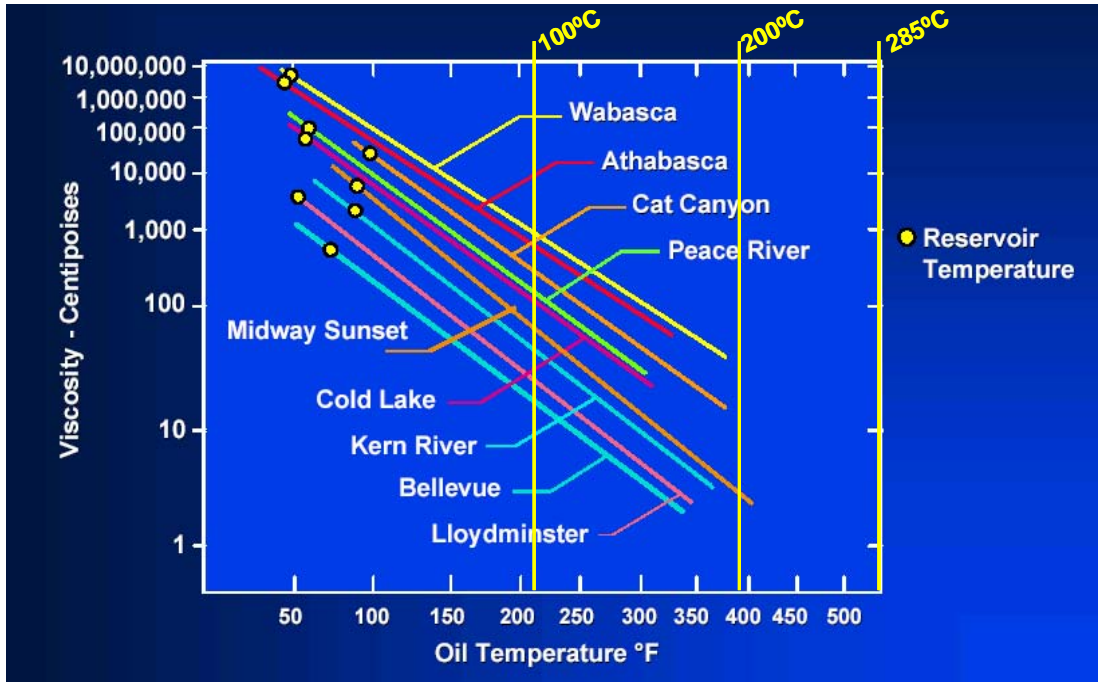

Figure 14. Relationship between temperature and viscosity in heavy oil (Source: Dusseault 2008a) 


\subsection{Steam Flooding}

The most basic form of thermal treatment technology is steam flooding, as shown in Figure 15. Steam is pumped through vertical injection wells into a heavy oil formation. The steam rises through the formation until it encounters a barrier, then spreads out laterally. The steam warms the heavy oil and drives it toward the production well. Natural gas is usually used to heat water to make steam. The cost of the natural gas compared to the amount of oil produced is an important consideration for steam flood operators.

California has nearly 25,000 produced water injection wells. The annual injected volume is approximately 1.8 billion bbl, distributed as follows: disposal wells - 360 million bbl; water flood — 900 million bbl; and steam flood — 560 million bbl (Stettner 2003). Figure 16 shows some wells operating under steam flood in the Wilmington field in southern California. In particular, the Kern River field benefitted tremendously from steam flooding. In the 1950s, primary production had dropped to about 10,000 bbl/day. Extensive steam flooding rejuvenated the field, resulting in production rates exceeding 130,000 bbl/day by the 1990s (Curtis et al. 2002).

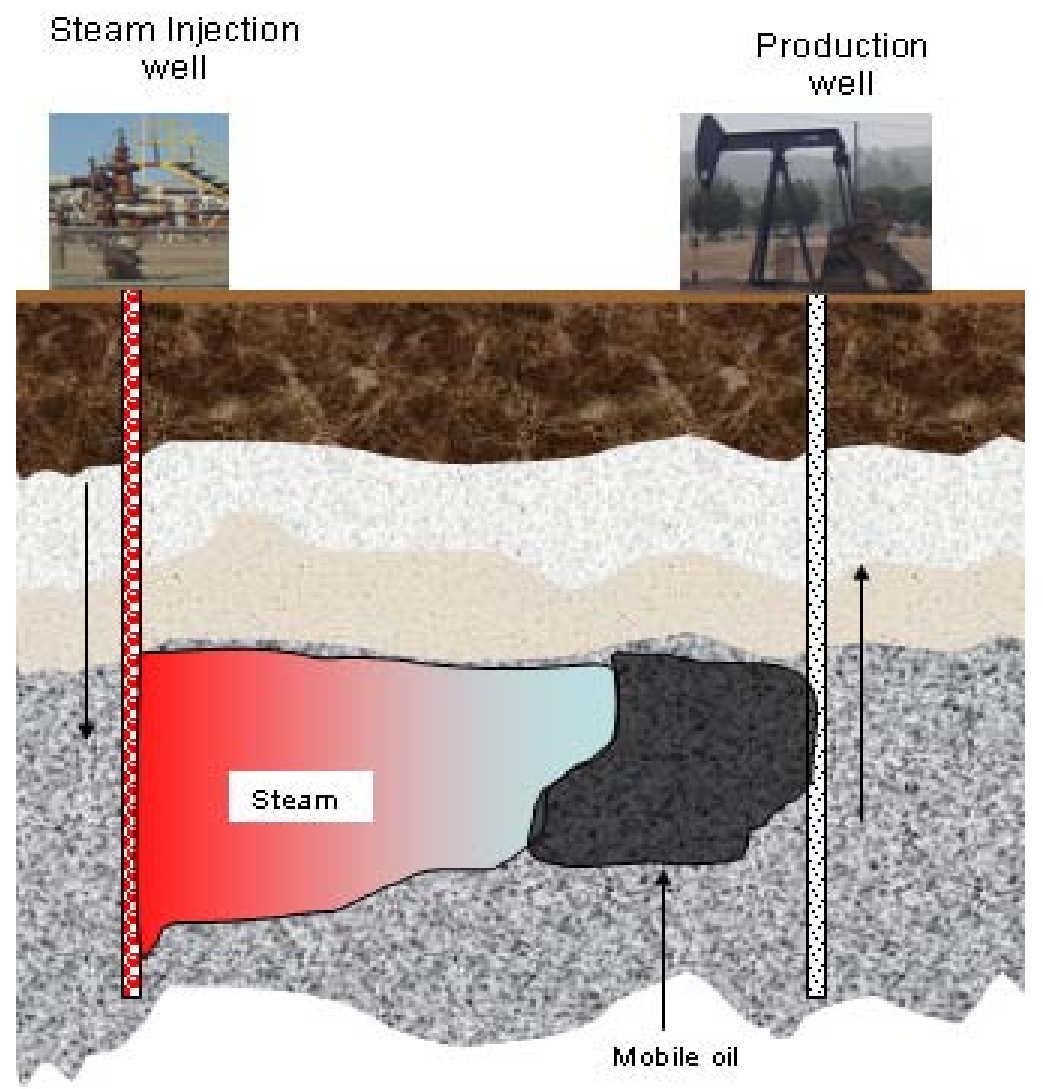

Figure 15. Diagram showing a steam flood operation 


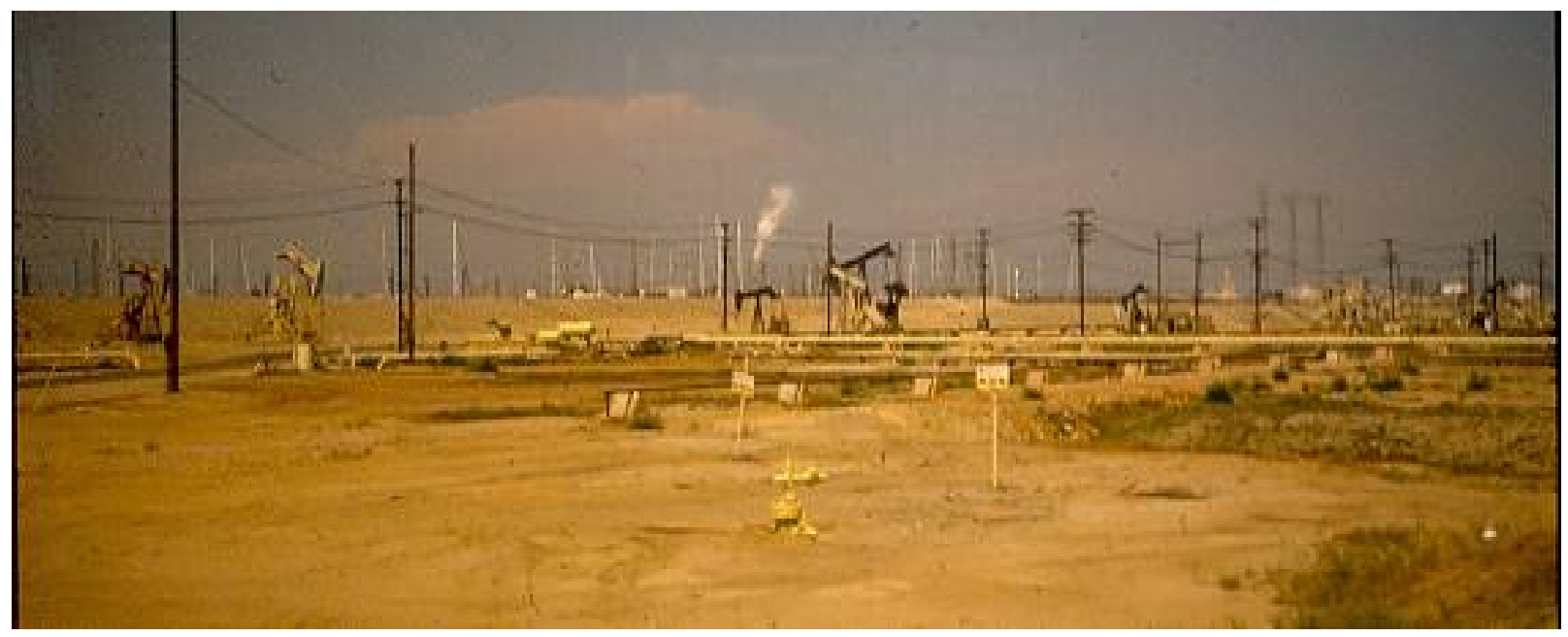

Figure 16. Steam flooding operations in Wilmington Field, California (Source: J. Veil, Argonne National Laboratory)

\subsection{Cyclic Steam Stimulation}

Cyclic steam stimulation (CSS) involves injecting steam into a single well, usually for several weeks. The steam is allowed to permeate into the formation and warm the bitumen. After that, the flow is reversed, such that bitumen is produced through the same well. Figure 17 shows the stages of steam injection, soaking, and production. CSS was developed in the 1960s for use at Imperial Oil Limited's Cold Lake deposit in Alberta (Hart Energy 2006).

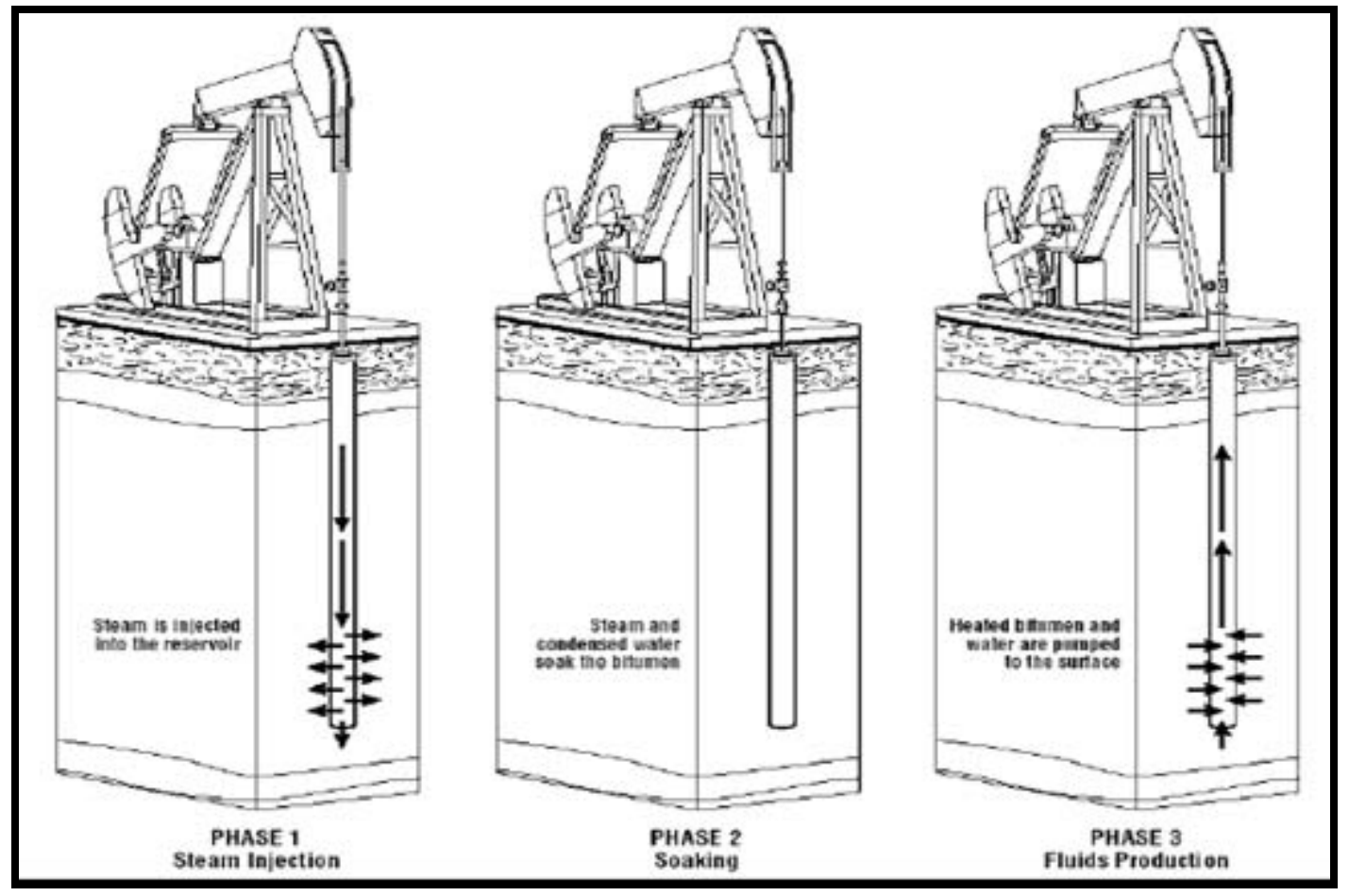

Figure 17. Traditional CSS process (Source: Dusseault 2008a) 
CSS, sometimes known as "Huff and Puff," is an older thermal technology that has some limitations. In order to inject enough steam fast enough to heat reservoirs operators may use injection pressures above the overburden stress, at least on the first few cycles. This can lead to fracturing of the formation and loss of steam. Steam rises rapidly in the reservoir because it is far lighter than the fluids. This creates unheated zones between wells and near the bottom of the formation. Differences in permeability creates inconsistent heating and subsequent movement of oil. Problems with well shearing, corrosion, and cement failure have been observed (Dusseault 2001). Isaacs and Yuan (2008) suggest that adding surfactant to the injected steam (a steam-foam process) will improve the sweep efficiency. Foam formation is a practical technique to significantly enhance the rate and extent of recovery from CSS.

According to Dusseault (2001), the best recovery ratios that can be expected in CSS are limited to about $15 \%$ in most reservoirs. In the exceptional reservoirs being produced by Imperial Oil Limited in Cold Lake, up to $30 \%$ of the oil is produced after 12 to 18 cycles of CSS (Dusseault 2008a). Dusseault also notes that although several CSS projects have been economically viable, they are taking place in intermediate viscosity reservoirs $(<100,000 \mathrm{cP})$. No thermal successes have been recorded in the Athabasca deposit, which is much more viscous (>500,000 cP). Hart Energy (2006) reports that the Cold Lake CSS operations produce about $150,000 \mathrm{bbl} /$ day of bitumen from more than 3,800 wells.

Dusseault (2008a) reports on several examples in which CCS was tried in horizontal wells (horizontal cyclic steam or HCS). Figure 18 shows a schematic of a horizontal cyclic steam well.

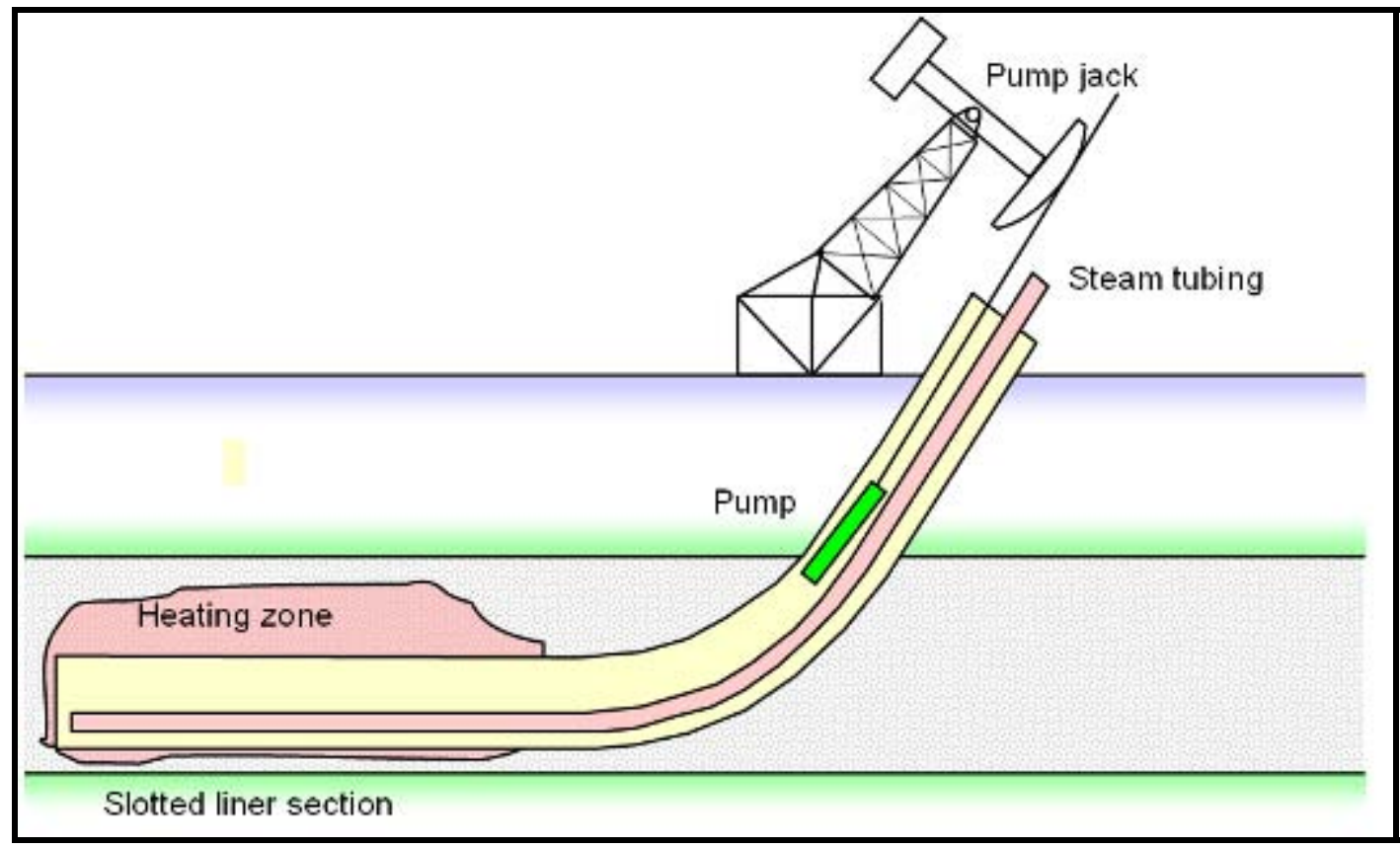

Figure 18. HCS well (Source: Dusseault 2008a) 


\subsection{SAGD}

Steam-assisted gravity drainage (SAGD) relies on a pair of horizontal wells spaced about 16 feet apart. A deeper production well is constructed near the bottom of the formation, and above it is a steam injection well. The upper steam well heats the formation, allowing the oil to flow by gravity to the lower production well (Figure 19).

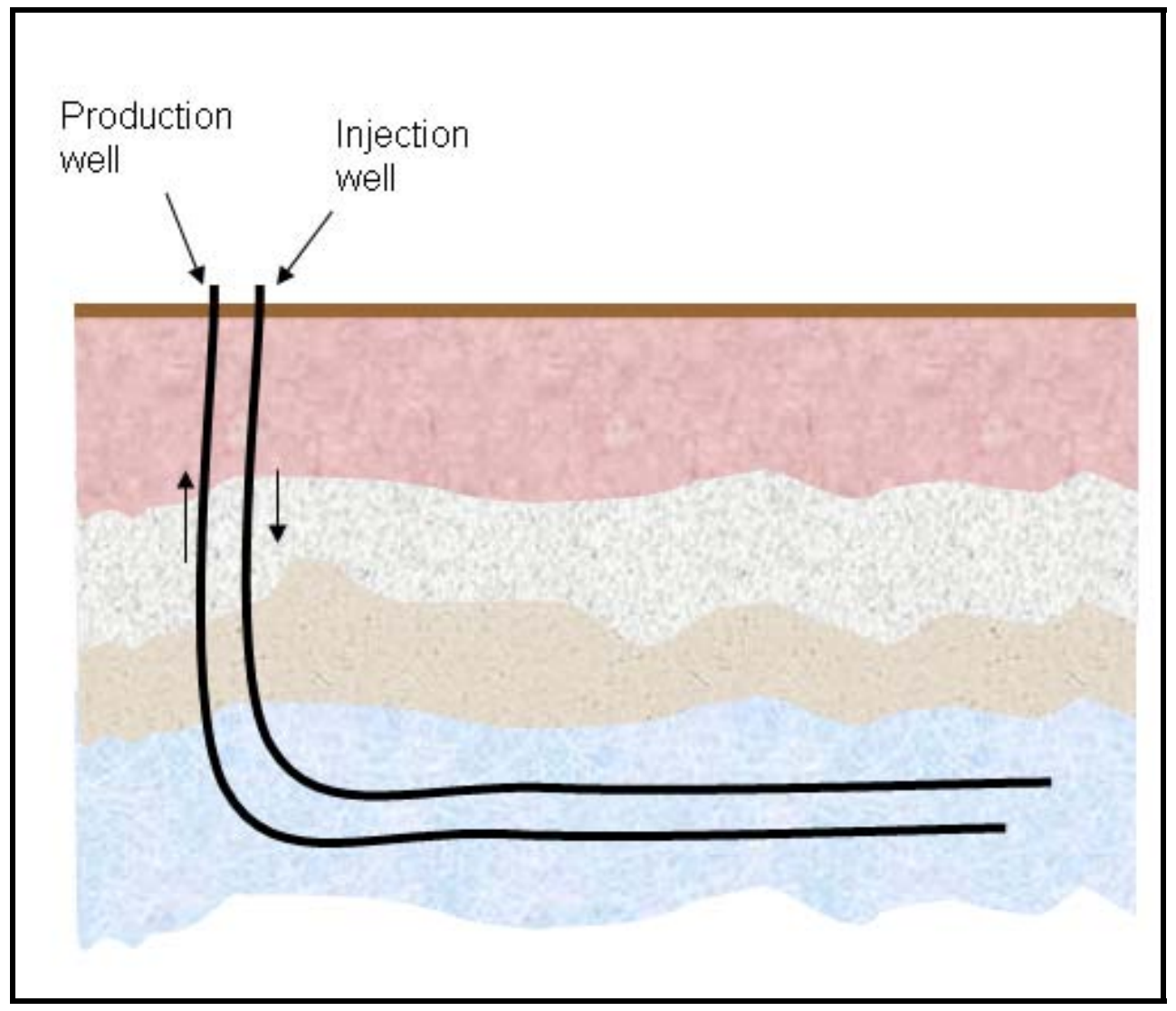

\section{Figure 19. Schematic drawing of dual wells in SAGD operation}

SAGD offers recovery rates of $50 \%$ of more of the original oil in place. It is a continuous process. SAGD works best in clean continuous sand formations (Hart Energy 2006).

One of the challenges in SAGD is to drill two horizontal wells that maintain a relatively constant vertical separation. Advances in horizontal drilling and downhole location sensing allowed SAGD to proliferate over the past decade.

Hart Energy (2006) describes key Canadian SAGD projects operated by EnCana, Petro-Canada, Husky Energy, Japan Canada Oil Sands Ltd (JACOS), Nexen, Total, Blackrock Ventures, and MEG Energy. These are primarily located in Alberta, with some production in Saskatchewan. Many of these projects are anticipated to produce more than 100,000 bbl/day of oil.

Many papers at the 2008 World Heavy Oil Congress focused on different aspects of SAGD. Quite a few of the papers reported on Canadian SAGD operations, while others described SAGD 
operations in Venezuela and China, as well as some SAGD modeling work on Brazilian reservoirs. Of particular relevance to this report on water issues, Mejia-Caña et al. (2008) discuss strategies to improve SAGD performance in reservoirs that have overlying water layers (top water). Based on modeling results, they suggest two methods for overcoming top water:

- Install a horizontal water production well at the base of the water zone to produce the water separately, or

- $\quad$ Place the injection and production wells closer together.

\subsection{Combustion Technologies}

Another approach to heating heavy oil is to burn part of the oil in place in the formation. The heat generated by this approach expands outward in the formation. In some applications combustion in the formation provides some upgrading of the bitumen.

One variant of combustion is known as Toe-to-Heel Air Injection (THAI ${ }^{\mathrm{TM}}$ ). THAI combines a vertical air injection well with a horizontal production well. For the first three months, steam is injected in the vertical well to heat the horizontal well and condition the reservoir around the vertical well. After the first three months, compressed air is injected in the vertical well and combustion is initiated. The combination of high pressure air and high temperature is usually adequate to self-ignite the formation, but in some cases operators have lowered electrical heaters or propane torches downhole to generate extremely hot, limited-volume areas around the well bore. When compressed air is added, initiation of combustion is immediate.

The combustion raises temperatures to approximately 400 to $600^{\circ} \mathrm{C}\left(750\right.$ to $\left.1,100^{\circ} \mathrm{F}\right)$. The combustion front moves from the "toe end" of the horizontal well to the "heel end" (Figure 20). It sweeps the oil to the collection well, ultimately capturing up to $80 \%$ of the original oil in place (Hart Energy 2006).

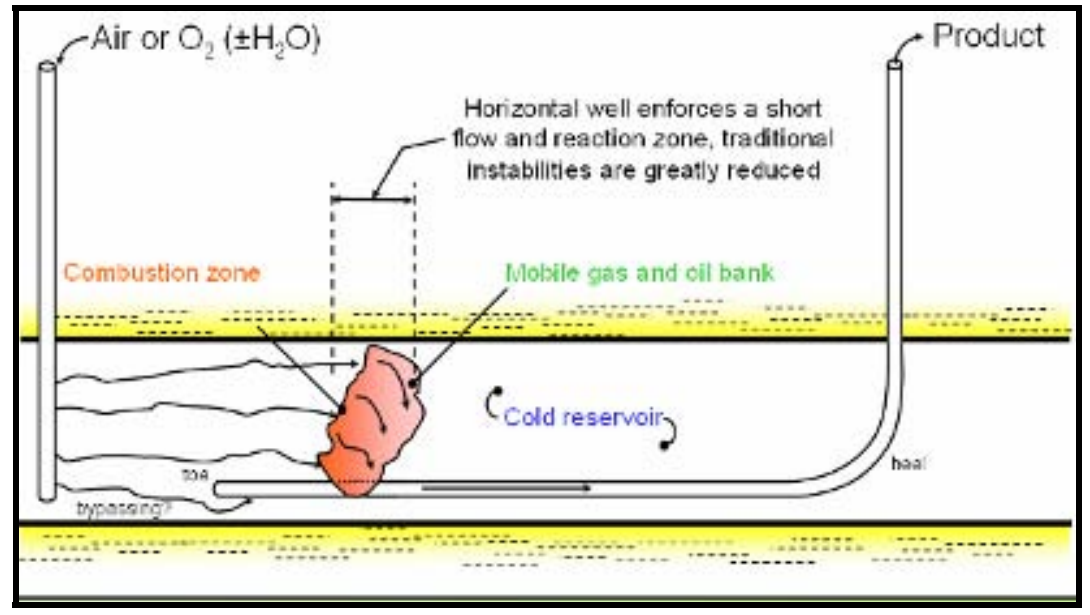

Figure 20. Schematic of the THAITM process (Source: Dusseault 2008a)

Figure 21 shows a group of THAI well pairs. A big advantage of THAI orientation is that the liquefied bitumen needs to travel only a short distance before reaching the production well. 


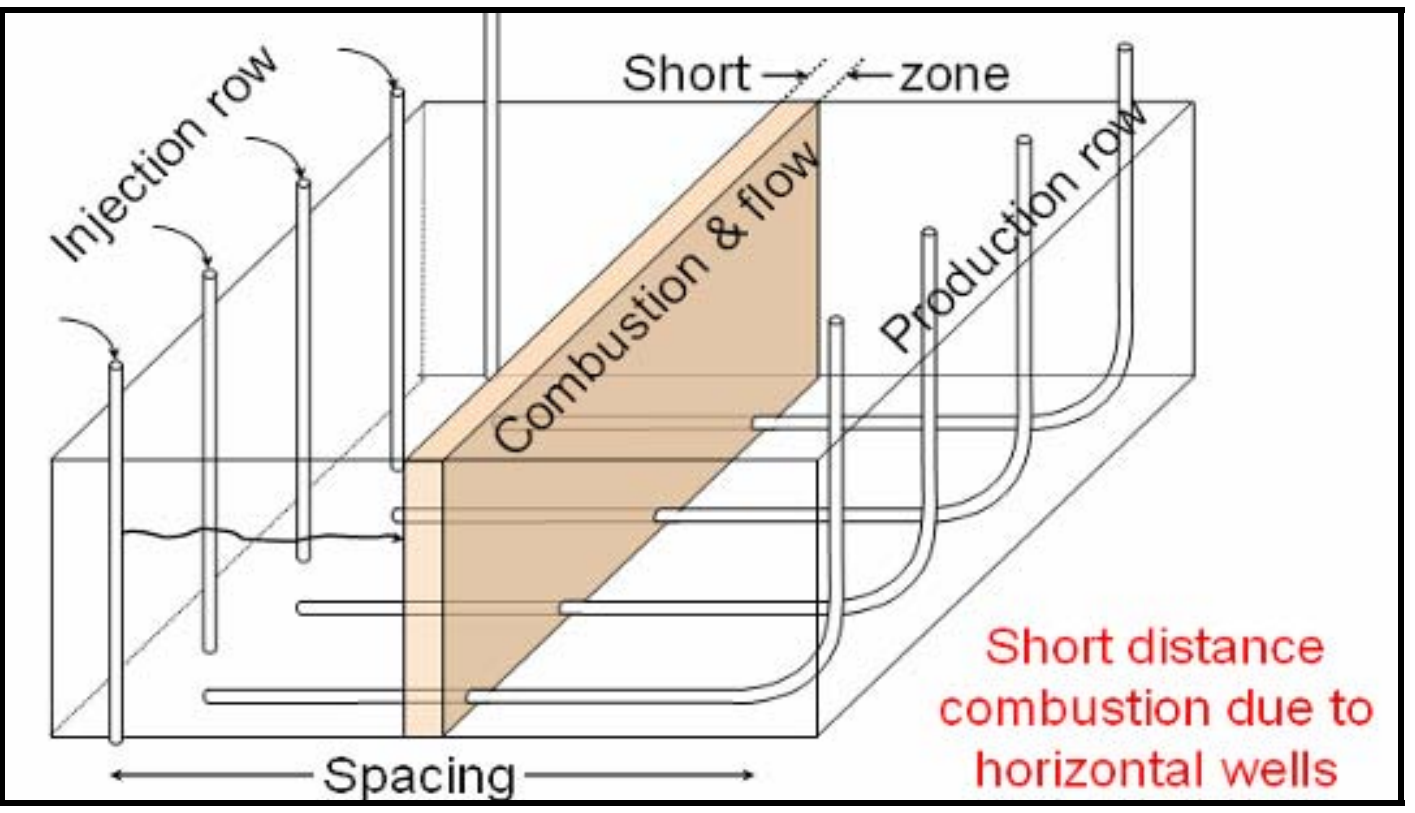

Figure 21. Schematic of THAI ${ }^{\mathrm{TM}}$ combustion process (Source: Dusseault 2008a)

The THAI process has the potential to produce from lower pressure and quality reservoirs, and from thinner or deeper reservoirs, than the steam-driven processes. Petrobank Energy and Resources Ltd. is conducting an experimental THAI project at Whitesands, in Alberta. The Whitesands project is designed around three well pairs producing to a central facility. Air injection commenced on the first well pair in July 2006. Air injection on the second well pair was initiated in December 2006 and on the third pair in June 2007 (Greaves et al. 2008). According to Petrobank (as reported in Hart Energy 2006), the Whitesands project was started by injecting steam through both injection and production wells for several months. The combustion reaction, when initiated, has strong heat but no flames. The vertical combustion front is expected to move laterally at about 10 inches per day. The heat causes the bitumen to soften. Bitumen, water, and gas will drain into the production well.

THAI offers some economic advantages (Dusseault 2008a):

- $\quad$ No need to purchase natural gas and obtain a large water supply to make steam (THAI production can yield one-third bbl of water for each bbl of oil produced),

- $\quad$ No large volume of solid waste like the sand from CHOPS production,

- $\quad$ The upgrading accomplished in the formation saves later surface upgrading costs, and

- $\quad$ Less $\mathrm{CO}_{2}$ is generated per bbl of oil produced.

The CAPRITM technology is an enhanced version of THAI. It provides additional bitumen upgrading capability by application of a gravel-packed catalyst between the tubing and the horizontal wellbore. API gravity increased laboratory tests of the CAPRI concept to light oil levels. The catalyst is comparable to the products currently used in refineries. Petrobank plans to 
install and test CAPRI ${ }^{\mathrm{TM}}$ in the second stage of its field pilots during 2008 and 2009 (Greaves et al. 2008).

\subsubsection{Composite or Sequenced Technologies}

The previous sections describe various technologies for producing viscous heavy oil and oil sands. Additional bitumen resources can be recovered by using several technologies at the same time or by using a second or third technology after an initial technology has produced its economic limit of bitumen.

Dusseault (2008b) describes the sequencing process. He starts with the recommendation that technologies that rely on gas drive energy within the formation (e.g., CHOPS or cold production) must occur first. Gas drive is a type of reservoir-drive system in which the energy for the transport and production of reservoir fluids is derived from the gas dissolved in the fluid. Thermal processes will deplete the gas drive. Once thermal processes have been used, the gas drive energy is depleted. He also recommends that combustion processes occur last in sequence because the high temperature resulting from combustion will make the formation too hot to use other methods.

Dusseault (2008b) offers some examples of how sequencing might be employed to extract residual bitumen left in the formation. For vertical wells, he suggests CHOPS, then CSS, then steam flood, then IGI, then combustion. For horizontal wells, he suggests cold production, then HCS, then SAGD or VAPEX, then IGI, then combustion. By utilizing both horizontal and vertical wells, other combinations of technologies and sequences of technologies are possible.

\subsection{Technologies for Producing Oil Shale}

Oil shale resources are developed though variations of two main technological approaches: mining with aboveground retorting, and in situ retorting methods. Both approaches require upgrading of the kerogen. Figure 22 (from DOE 2004) shows the steps for converting oil shale to finished products.

Because no oil shale is currently produced in North America and limited amounts are produced elsewhere, the technologies described here are proposed technologies that are likely to be used if or when oil shale is actually produced on a large scale. The following discussions on oil shale mining, retorting, and upgrading are based on information in BLM (2008) and Veil and Puder (2006).

\subsubsection{Mining for Oil Shale}

Mining of oil shale can take place using surface mining techniques (e.g., strip mining and/or open pit mining) or subsurface mining techniques (e.g., room-and-pillar mining or longwall mining). The decision regarding surface or subsurface mining rests largely on the depth of the resource (and the corresponding thickness of overburden) and economic factors. 


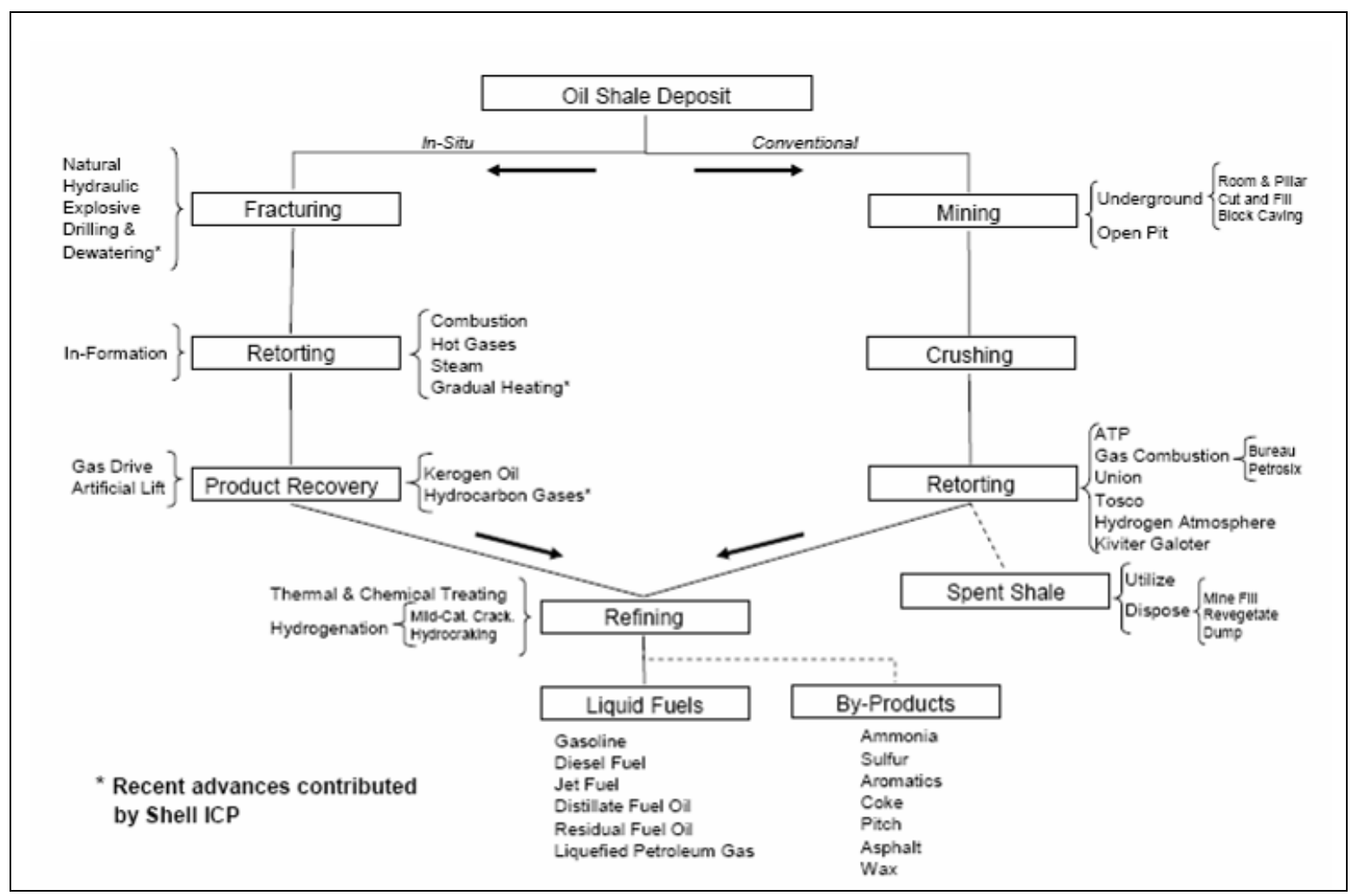

Figure 22. Generalized processes for conversion of oil shale to fuels and by-products (Source: DOE 2004)

\subsubsection{Surface Mining for Oil Shale}

Mining techniques and equipment are similar to those developed for the coal industry. Strip mining, for example, can be used for near-surface oil shale deposits. In this approach, draglines, shovels, and/or bucket-wheel excavators are used to remove material. Explosives or highpressure water injection (hydrofracturing) are optional techniques for loosening material in surface mining operations. Trucks and/or conveyors are needed to move excavated material.

Surface mines require storage areas for stockpiling of overburden. Operations may be conducted in a manner to allow retort ash to be disposed of in previously excavated areas.

\subsubsection{Subsurface Mining for Oil Shale}

Subsurface mining may be carried out in locations where the oil shale resource is deep enough to prohibit economical surface mining, or where the resource crops out on a valley wall. The roomand-pillar approach to subsurface mining involves excavating rooms and leaving undisturbed formations as pillars to support the overburden.

The typical cycle of activities in room-and-pillar mining involves drilling, charging, blasting, wetting, crushing, loading, hauling, scaling, and roof bolting (DOE 1982). Ventilation is 
required, and methane gas may be present. Pumping systems are typically needed for managing formation water.

Equipment necessary to support underground mining includes conveyor systems, crushing systems, and haulage systems. Explosives are typically used to reduce the formation to rubble prior to crushing. Typically, primary and even secondary crushing are conducted within the mine before oil shale is brought to the surface. Subsurface mining requires storage areas for stockpiled oil shale and for spent shale from the aboveground retort. Some portion of the spent shale may be returned to the mine for disposal, but operations will ultimately have a net accumulation of spent shale on the surface to be managed.

\subsubsection{In Situ Technologies for Producing Oil Shale}

This group of technologies involves heating oil shale in place to liquefy the kerogen, then extracting the oil from the ground and transporting it to an upgrading facility. Several technologies can be used to heat the oil shale and several others can be used to aid in extraction of the oil.

Many of the likely technologies for producing oil shale in situ are similar to those used to produce viscous heavy oil and oil sands. Because these were discussed in previous sections of the report, little additional discussion of those technologies is included here.

\subsubsection{Technologies for Heating Kerogen}

The kerogen in an oil shale formation is naturally immobile. In situ techniques for heating and extracting the kerogen rely on heating the formation in place to decompose the kerogen into more mobile liquid and gaseous organic fractions that can then be collected using conventional oil and gas recovery techniques. The success of in situ techniques may be enhanced through the use of explosives or hydrofracturing to increase the permeability of the formation and thereby promote the flow of the mobilized kerogen to collector wells.

The early versions of in situ retorting technology involved burning a portion of the oil shale underground to produce the heat needed for retorting the remaining oil shale. Explosives were used to reduce the formation to rubble, then 10 to $30 \%$ of the volume of the formation was mined using conventional techniques (and processed in an aboveground retort) to create voids that serve as retorting chambers. Next, the formation was heated, and the mobilized kerogen was collected. Later developments relating to in situ techniques have involved heating not only to promote flow of the kerogen, but focus on heating at sufficient temperature and duration to promote in situ chemical transformations (pyrolysis) of the kerogen. Heat can be added through the use of injection of steam or other fluids via vertical or directionally drilled wells. Alternative electromagnetic heating methods include microwave heating, radio-frequency (RF) heating or electric resistance heating.

\subsection{Electromagnetic Heating}

At a sufficiently high power level, electromagnetic energy can be used to heat the formation. Specific energies may include low-frequency electric resistivity heating or higher-frequency radio-wave and microwave heating. Electromagnetic heating has the potential to be used in formations where steam injection would not be successful, e.g., low-permeability formations, 
thin or highly heterogenous formations, or especially deep formations. It could be used in tandem with other enhanced oil recovery technologies.

Raytheon (Cogliandro 2006, Raytheon 2006) developed a radio frequency (RF) heating technology. Field tests have shown that the rapid heating and volatilization of formation water causes microfracturing of the formation, leading to increased permeability and product recovery. An overburden thickness of 150 feet is required to prevent induced RF energy from reaching the surface. Raytheon has had a recovery rate of $75 \%$ using $R F$, and some upgrading of the initial kerogen pyrolysis products has been observed. When combined with $\mathrm{CO}_{2}$ injection, recovery rates as high as 90 to $95 \%$ have been obtained.

\subsection{Shell ICP}

Shell Oil has developed an in-situ retorting process known as thermally conductive in-situ conversion process (ICP). The process involves heating underground oil shale by using electric heaters placed in deep vertical holes drilled through an entire vertical section of oil shale. The volume of oil shale is heated over a period of two to three years, until it reaches $650-700^{\circ} \mathrm{F}$, at which point oil is released from the shale. The released product is gathered in collection wells positioned within the heated zone.

For its proposed project in Colorado, Shell plans to pump refrigerated fluid through a series of wells drilled around the perimeter of the extraction zone to establish an underground barrier called a freeze wall. A series of 150 holes approximately 8 feet apart would be drilled where the freeze wall would be created. The freeze holes would be drilled to a depth of approximately 1,850 feet. A chilled fluid $\left(-45^{\circ} \mathrm{F}\right)$ would be circulated inside a closed-loop piping system and into the holes. The cold fluid would freeze the nearby rock and groundwater and, in 6 to 12 months, create a wall of frozen ground. The freeze wall would be maintained during both the production and reclamation phases of the ICP project (BLM 2008). The freeze wall would prevent groundwater from entering the extraction zone and keep hydrocarbons and other products generated by the in-situ retorting from leaving the project perimeter. Before the heating process begins, the groundwater inside the freeze wall will be pumped out and injected into a nearby aquifer.

Shell has undertaken several research projects on private land in Colorado, including heating through the ICP process. Limited testing of freezing technology has been completed. The current study is a test of the freeze wall on a larger scale. Freezing at this site began in 2007, and testing is expected to continue until approximately $2010 .{ }^{6}$

\subsubsection{Technologies for Aiding Extraction of Kerogen}

Kerogen extraction technologies are similar to those used to produce other forms of heavy oil and may also resemble techniques used for enhanced recovery of conventional oil. The most likely technologies include steam flooding, solvent injection, and $\mathrm{CO}_{2}$ flooding. In some cases, water flooding may work.

\footnotetext{
${ }^{6}$ See

http:/www.shell.com/home/content/usa/aboutshell/shell_businesses/upstream/locations_projects/onshore/mahogany /mahogany_media.html. Accessed September 5, 2008.
} 


\subsection{Steam Flooding}

CSS, described in section 3.1.2.2.2, could be applied to oil shale production. The process would consist of repeated injections of high-pressure steam, causing fractures in the formation and decreased viscosity of the kerogen. Recovery wells would collect both the kerogen and the steam condensate.

SAGD, described in section 3.1.2.2.3, is used extensively in the oil sand industry. SAGD differs from CSS in that SAGD relies on a pair of horizontal wells. A deeper production well is constructed near the bottom of the formation, and above it is a steam injection well. Following establishment of circulation between the wells, the process results in collection of heated hydrocarbon, steam condensate, and formation water by the production well. SAGD may be applicable for oil shale production too.

\subsection{Solvent Injection}

Solvent injection is similar to steam flooding, but relies on chemical dissolution of the kerogen by chemicals, rather than on steam. It may be performed using various well configurations, including a pair of horizontal wells, as described for SAGD above. Solvent flooding has the benefits of requiring no water and potentially yielding higher recovery rates of kerogen. However, the solvent must be sufficiently recoverable for the process to be economical, and any unrecovered solvent must not pose an environmental threat to groundwater.

\subsection{High-Pressure $\mathrm{CO}_{2}$ Flooding}

This technology is the injection of $\mathrm{CO}_{2}$ following in-situ retorting and provides enhanced removal of kerogen decomposition products. The additional benefit is the sequestration of $\mathrm{CO}_{2}$ in the formation, providing a means of managing the $\mathrm{CO}_{2}$ produced by the retorting or the formation heating infrastructure.

\subsubsection{Retorting and Upgrading}

Kerogen from oil shale is not directly usable as crude oil. Before it can be sent to a refinery, kerogen must be retorted and upgraded. Retorting is the heating of the oil shale to separate the organic and inorganic fractions, as thermal desorption drives the organics from the mineral matter. Initial pyrolysis takes place during retorting. Upgrading is designed to increase the relative proportion of saturated hydrocarbons over unsaturated hydrocarbons in the crude shale oil recovered from retorting and to eliminate those other compounds present that can interfere with further refining of the crude shale oil into conventional middle distillate fuels (primarily compounds containing nitrogen or sulfur atoms). The upgrading steps are comparable to those used in refining (e.g., distillation, delayed coking, catalytic hydrogenation, and hydrogen production).

\subsubsection{Retorting}

After being mined, the oil shale must be heated to a high temperature $\left(900-1,000^{\circ} \mathrm{F}\right)$ to separate the kerogen from the oil shale. The process is known as pyrolysis. Alternative retort technologies are differentiated by how they produce and deliver the heat needed for pyrolysis. Technologies include both direct and indirect heating of the oil shale. 
Some examples of aboveground retorts include:

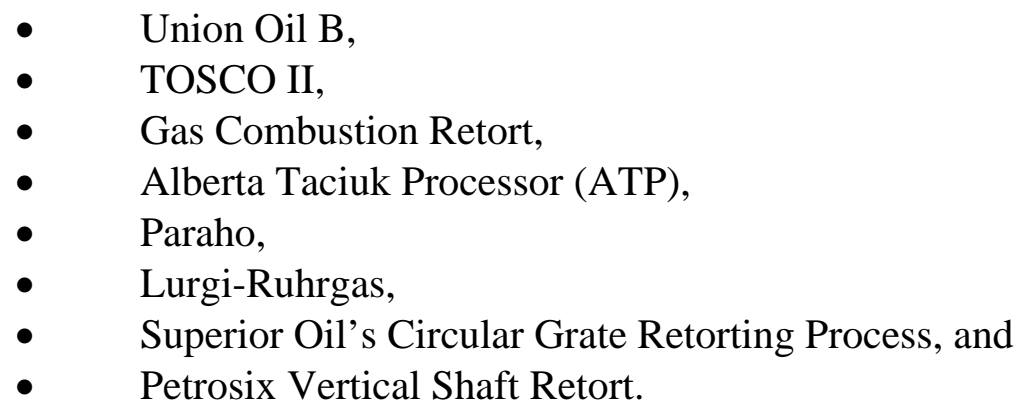

More information on these technologies is available in BLM (2008), DOE (2004), RAND (2005), and DOI (1973a).

Because of the heterogeneity of oil shale and other site-specific factors, specific technologies may be better suited for some locations than others. Retorts require electric power, a source of heat, and water for processing. Crushing of mined shale is necessary, with the particle size dependent on the retort's requirements.

Retorting leads to three products: crude shale oil, hydrocarbon gases, and char. Char is organic matter that remains absorbed to the mineral fraction of the shale. It may be burned as an energy source for the retort.

For in situ approaches, the liquefied kerogen and water are pumped to the surface. The water originates as a combination of formation water, water produced in kerogen pyrolysis, and condensate from any steam flooding. The kerogen and water must be separated prior to further processing. While in situ techniques achieve some degree of pyrolysis, aboveground retorting may be necessary to complete the pyrolysis of the kerogen.

The in situ approach offers several advantages over mining and aboveground retort:

- $\quad$ Eliminated or reduced material handling requirements and spent shale disposal,

- $\quad$ Accessibility of greater portions of the deposit for economical kerogen recovery (although perhaps at a lower overall recovery efficiency),

- $\quad$ Significantly reduced air and noise pollution,

- $\quad$ Reduced impacts on ecosystems because of the smaller aerial extent of surface industrial activities and the eliminated or reduced land area required for material stockpiles and solid waste disposal, and

- $\quad$ Reduced surface water quality impacts because of the reduced size of land disposal areas and the reduced potential for stormwater pollution from interim material and waste pile runoff.

In situ retorting also has some potential disadvantages. Difficulty in maintaining precise heat control could reduce the yield of hydrocarbons. The duration of in situ formation heating and the energy costs may be prove uneconomical. Impacts on groundwater flow patterns and quality 
could be significant due to changes in formation permeability and the potential for leaching of chemicals from retorted zones. Subsidence could also be an issue.

\subsubsection{Upgrading}

The different retorting processes yield shale oils having different properties. Independent of the specific process used for retorting, the shale oil is likely to require further processing or upgrading before becoming attractive to oil refineries as feedstocks for conventional fuels. Upgrading is designed to increase the relative proportion of saturated hydrocarbons over unsaturated hydrocarbons in the crude shale oil recovered from retorting, and to eliminate those other compounds present that can interfere with further refining of the crude shale oil into conventional middle distillate fuels (primarily compounds containing nitrogen or sulfur atoms). The upgrading steps are comparable to those used in refining (e.g., distillation, delayed coking, catalytic hydrogenation, and hydrogen production). 


\section{Chapter 4 - Water Issues}

Heavy oil production involves either mining large tracts of land, which results in surface disturbance, or drilling of numerous injection and recovery wells for in situ production. Both methods have the potential to cause impacts to ground and surface water resources. In addition, large-scale production of heavy oil resources will require local availability of large volumes of water to support the production process. This chapter discusses some of the water usage, water needs, and water quality issues relating to heavy oil production. Much of the material relating to oil shale and oil (tar) sands comes from earlier documents co-authored by the authors of this report (Veil and Puder 2006; BLM 2008).

\subsection{Water Usage in Heavy Oil Production}

Water is used for various process and non-process purposes at heavy oil production facilities. While describing the different water uses, it is useful to evaluate the volume of water needed to support the various uses.

\subsubsection{Conversion of Volume Units}

Liquid volumes in the United States are expressed in several common units (e.g., gallons, barrels, acre-ft). Depending on the literature source, volumes may be expressed in any of these units or in metric units, like $\mathrm{m}^{3}$. Before moving into the water uses and required volumes in the next section, this section offers some conversion factors:
a) 1 barrel $=42$ gallons $=0.16 \mathrm{~m}^{3}$
b) 1 acre-foot $=325,851$ gallons $=7,760 \mathrm{bbl}=1,233 \mathrm{~m}^{3}$
c) 1 million bbl/day = 47,085 acre-feet/yr = 42 million gallons per day (MGD)
d) $1 \mathrm{MGD}=1,120$ acre-feet/yr $=24,000 \mathrm{bbl} /$ day
e) $1 \mathrm{~m}^{3}=6.3 \mathrm{bbl}=264.2$ gallons

\subsubsection{Non-Process Water Uses}

The heavy oil industry requires water for many non-process purposes that are applicable to nearly all production methods. Some of the uses directly support human needs, such as drinking water supply, toilets, showers, and laundries. Some of this water is needed at the job site, while other water is needed to support the living accommodations for the employees, presumably at an off-site but nearby location. Water is also needed to provide support and safety functions, such as dust control and fire protection water. If reclamation of the land surface is undertaken following the end of production, irrigation water may be necessary.

To the extent that heavy oil production requires power generation from on-site or nearby facilities, large volumes of water may be needed to support the power plant. A new power plant or increased capacity at an existing plant would require water for steam generation, scrubber operations, cooling systems, and dust control. 


\subsubsection{Process Water Uses}

Process water use involves water that is a direct part of getting the heavy oil from the ground or in retorting or upgrading it.

\subsubsection{Process Use for Viscous Heavy Oil and Oil Sands Production}

Viscous heavy oil is produced via in situ processes. Steam is used to lower the viscosity of heavy oil, and water can be used to move heavy oil. Water may also be needed for hydrofracturing the formation to promote better fluid movement. Water is needed for steam production for steam flooding, CSS, and SAGD. Other water is used for water flooding and for WAG processes. Water may also be necessary to cool machinery used at the surface.

Much of the water used in these "wet" processes is recaptured along with the produced heavy oil. This "used" or "produced" water contains various contaminants that may interfere with subsequent reuse. Generally, some form of treatment is required prior to reuse. A "dry" combustion process like THAI may generate surplus water originating as formation water or as a product of combustion.

When oil sands are produced through an in situ process, water is used in the same ways described above. Some oil sands are mined, however. Because of their limited strength and stability, oil sands are generally mined through surface mines only. Water uses for a surface mine with surface retort could include:

- Water for mining and drilling operations,

- $\quad$ Cooling of equipment,

- $\quad$ Transport of ore and spent material, including the option of hydrotransport of tar sand slurry,

- $\quad$ Dust control for surface mines, crushers, overburden and source rock storage piles, and retort ash piles,

- $\quad$ Cooling of spent material exiting the retort, and

- Wetting of spent material prior to disposal.

\subsubsection{Process Use for Oil Shale Production}

Oil shale mining may take place in surface mines or underground mines. Water uses for a surface or underground mine with surface retort are similar to those described in the previous section for oil sands mining.

For in situ projects, water may be needed for:

- Hydrofracturing,

- $\quad$ Steam generation,

- Water flooding,

- $\quad$ Quenching of kerogen products at producer holes,

- $\quad$ Cooling of productive zones in the subsurface,

- $\quad$ Cooling of equipment, and

- $\quad$ Rinsing of oil shale after the extraction cycle. 
Depending on the quality of the shale oil produced directly from in situ processes, water may be required for additional processing of the product at the surface.

\subsubsection{Dewatering Issues}

Dewatering systems would need to be in place to support most surface mining or underground mining. Dewatering could affect the availability of domestic or municipal wells in the vicinity, leading to reduced flow or dry wells due to depression of local groundwater levels. Springs could likewise be affected. The in situ approach also requires dewatering within each treatment volume. Water removed for the purpose of dewatering could be used for site purposes such as process water or dust control, though the quality of the water (e.g., TDS) may limit its usefulness. Excess water from dewatering operations may be discharged to surface waters (as permitted by local and national regulations; treatment may be necessary) or injected into a deeper formation (again, as permitted). Subsidence occurring due to the dewatering is a possibility.

\subsection{Water Quantity Needs for Heavy Oil Production}

A large amount of water is required during the operations phase. The literature provides some actual examples of water use, but most of the volume estimates are projections. They are generic estimates that will vary based on site-specific factors.

\subsubsection{Water Needs for Viscous Oil and Oil Sands Production}

As noted in Chapter 3, California injects a large volume of water each year to enhance oil production. Much of this water, particularly the 560 million bbl/year of steam flood (Stettner 2003), is used to support heavy oil production. Much of the injected steam subsequently is brought to the surface as produced water. Chevron's operations in the Kern River field produced 900,000 bbl/day of water, with a ratio of 9 bbl water to $1 \mathrm{bbl}$ oil. Waldron (2005) notes that Chevron reclaims about half of this water for reuse in boilers to make more steam. The remaining volume of water is treated and made available to local farmers for irrigating grapes, citrus fruit, almonds, and pistachios. The treated produced water is blended with other fresh water sources to lower the concentration of boron to avoid leaf and plant damage (Waldron 2005; Brost 2002).

Hart Energy (2006) reports that Imperial's CSS operations at Cold Lake inject between 500,000 to 750,000 bbl/day of water as steam. Initially, Imperial injected 5 or $6 \mathrm{bbl}$ of water to produce $1 \mathrm{bbl}$ of oil. Current water use is much lower - less than $2 \mathrm{bbl}$ of water per bbl of oil. Up to $95 \%$ of the water injected as steam is recycled.

BLM (2008) provides estimates for the water requirements of a 20,000 bbl/day tar sand operation relying on four technology options. The estimates take into account process water, mining (if applicable) needs such as dust control and potable water. Values were determined for various specific technology applications. For in situ production with steam injection following the SAGD technology, the estimated water requirement is typically 520 acre-feet/year. Although SAGD has a start-up phase requiring water at a much higher rate, recovery and reuse of steam along with formation water accounts for the longer-term SAGD rate of 520 acre-feet/year. For steam injection relying on CSS, the estimated rate is 3,810 acre-feet/year. In situ combustion, which considers the benefits of dewatering and produced water, has a net requirement of 44 acre-feet/year. The surface mine with surface retort estimate ranges from 2,160 to 
5,410 acre-feet/year, while the surface mine with solvent extraction option estimate ranges from 1,070 to 2,250 acre-feet/year plus additional water for the upgrading process. The ranges are due to variations in technologies.

Kus (2008) describes StatoilHydro's efforts to find water for a SAGD operation in Alberta. There was no fresh surface water source available nearby, so the company used brackish groundwater to make the steam. In order to treat the brackish water, StatoilHydro used a warm lime softening process followed by cationic ion exchange. The company is also studying an evaporator/crystallizer system to manage the concentrated byproducts from treatment and reduce the volume of makeup water by $40 \%$.

Portelance (2008) also describes technologies for treating water produced from SAGD operations to make it clean enough to produce boiler feed water. He recommends using sulfuric acid and magnesium oxide.

Mikula et al. (2008) report that surface-mined bitumen in Canada uses 12 bbl of water for each bbl of bitumen recovered. However, much of the water is recovered, resulting in a net usage of $4 \mathrm{bbl}$ of water per bbl of bitumen. Most of this water is left in the pore spaces of the mineral tailings left behind. Their paper discusses alternative methods for managing the tailings that could allow a greater proportion of recycling of the water. Although such methods are technically feasible, they present a trade-off. As more of the water gets recycled, the concentrations of dissolved constituents increases, thereby reducing the effectiveness of reusing that water for bitumen recovery.

Canadian oil sands are "water-wet" (i.e., a layer of water surrounds the sand grain, with the bitumen partially filling the voids between the wet grains), which allows for separation of bitumen from the sand using hot water. After mining, the oil sands are transported to an extraction plant, where a hot water process separates the bitumen from sand, water, and minerals. The separation takes place in separation cells. Hot water is added to the sand, and the resulting slurry is piped to the extraction plant where it is agitated. The combination of hot water and agitation releases bitumen from the oil sand.

A different type of water issue is found in the Faja heavy oil region in Venezuela. Petrocedeño produces heavy oil (8.4 $4^{\circ}$ API gravity) through about 350 horizontal wells. Inizan et al. (2008) report that 195,000 bbl of heavy viscous oil is produced each day along with 130,000 bbl of water from a large regional aquifer. These wells are more like traditional oil wells that generate substantial volumes of produced water. Petrocedeño implemented an adaptive water production policy to optimize oil production while minimizing water production. Producing wells are monitored weekly to measure water production. Temperature-profiling optical fibers are inserted into the wells to identify any new water entry points.

\subsubsection{Water Needs for Oil Shale Production}

DOI (1973b) contains extensive discussion of water requirements at a hypothetical 100,000-bbl/day oil shale plant associated with a surface mine and a 50,000-bbl/day plant associated with an underground mine. DOI (1973a) compiles these two examples plus comparable data for three other types of oil shale plants. This information is shown in Table 1. 
Table 1. Water Requirements for Different Types of Oil Shale Plants (in acre-feet/year)

\begin{tabular}{|l|l|l|l|l|l|}
\hline $\begin{array}{l}\text { Type of } \\
\text { Production } \\
\text { (bbl/day) }\end{array}$ & $\begin{array}{l}\mathbf{5 0 , 0 0 0} \\
\text { Underground }\end{array}$ & $\begin{array}{l}\mathbf{1 0 0 , 0 0 0} \text { Surface } \\
\text { Mine }\end{array}$ & $\begin{array}{l}\mathbf{5 0 , 0 0 0} \text { In } \\
\text { Situ }\end{array}$ & $\begin{array}{l}\mathbf{4 0 0 , 0 0 0} \\
\text { Technology Mix }\end{array}$ & $\begin{array}{l}\mathbf{1 , 0 0 0 , 0 0 0} \\
\text { Technology Mix }\end{array}$ \\
\hline Process Uses & & & & & \\
\hline $\begin{array}{l}\text { Mining and } \\
\text { Crushing }\end{array}$ & $370-510$ & $730-1,020$ & n/a & $2,600-3,600$ & $6,000-8,000$ \\
\hline Retorting & $580-730$ & $1,170-1,460$ & n/a & $4,100-5,100$ & $9,000-12,000$ \\
\hline $\begin{array}{l}\text { Shale Oil } \\
\text { Upgrading }\end{array}$ & $1,460-2,190$ & $2,920-4,380$ & $1,460-2,200$ & $11,700-17,500$ & $29,000-44,000$ \\
\hline $\begin{array}{l}\text { Processed Shale } \\
\text { Disposal }\end{array}$ & $2,900-4,400^{\text {a }}$ & $5,840-8,750^{\text {a }}$ & n/a & $20,400-30,900$ & $47,000-70,000$ \\
\hline & \multicolumn{5}{|l|}{} \\
\hline $\begin{array}{l}\text { Non-Process } \\
\text { Uses }\end{array}$ & \multicolumn{5}{|l|}{} \\
\hline $\begin{array}{l}\text { Power } \\
\text { Production }\end{array}$ & $800-1,110$ & $1,570-2,190$ & $800-1,900$ & $6,300-9,800$ & $16,000-25,000$ \\
\hline Revegetation & $0-700$ & $0-700$ & $0-700$ & $0-4,900$ & $0-12,000$ \\
\hline Sanitary & $20-50$ & $30-70$ & $20-40$ & $200-300$ & $1,000-1,000$ \\
\hline Domestic & $670-910$ & $1,140-1,530$ & $720-840$ & $5,400-6,900$ & $13,000-17,000$ \\
\hline
\end{tabular}

${ }^{a}$ Assumes that water used is $20 \%$ by weight of the disposed spent shale

Source: Based on DOI (1973b)

Although water supplies are needed to produce oil shale, some steps in the process actually generate water. Water is an inherent by-product of oil shale retorting. It may be produced at a rate as high as 10 gallons per ton of shale retorted; but more typically, it will range from 2 to 5 gallons per ton. It will contain a variety of organic and inorganic components (DOI 1973a). Before it can be reused or discharged, it will require treatment.

BLM (2008), noting uncertainty in process water requirements, assumed for Colorado-UtahWyoming oil shale operations that 2.6 to $4.0 \mathrm{bbl}$ of water could be required for each barrel of shale oil produced from a surface or subsurface mine with surface retort. Assuming an operation with a production rate of 50,000 bbl/day, BLM (2008) estimated a range in water demand of 6,100 to 9,400 acre-feet/year, with a consumption rate of 4,600 to 7,100 bbl/day. (Demand indicates total extracted surface water and groundwater, while consumption is the net water use, assuming return of treated water to original source.) When the operational water requirements are combined with sanitary and potable water needs, the corresponding consumption rate is estimated at 4,900 to 7,400 acre-feet/year.

BLM (2008) estimated that 1 to $3 \mathrm{bbl}$ of water could be required for each barrel of oil shale produced from in situ projects. Assuming an in situ operation with a production rate of 200,000 bbl/day, BLM (2008) estimated a range in water demand of 7,100 to 28,200 acre-feet/year, with a consumption rate of 5,400 to 21,400 bbl/day. When the operational water requirements are combined with sanitary and potable water needs and the water 
requirements of a coal-fired power plant, the corresponding consumption rate is estimated at 18,600 to 34,600 acre-feet/year.

Different authors over the years have made different estimates of water requirements for oil shale development. Table 2 compares some of those estimates.

Table 2. Comparison of Water Requirements Estimated by Different Authors

\begin{tabular}{|c|c|c|c|}
\hline Source & Oil Production (bbl/day) & $\begin{array}{l}\text { Water Required (acre- } \\
\text { feet/year) }\end{array}$ & $\begin{array}{l}\text { Water Requirement Scaled to } \\
100,000 \text { bbl/day Oil } \\
\text { Production (acre-feet/year) }\end{array}$ \\
\hline Prien $(1954)^{\mathrm{a}}$ & 1 million & $\begin{array}{l}\text { 227,000 diverted } \\
82,500 \text { consumed }\end{array}$ & $\begin{array}{l}\text { 22,700 diverted } \\
8,250 \text { consumed }\end{array}$ \\
\hline $\begin{array}{l}\text { Cameron and Jones } \\
(1959)^{\mathrm{a}}\end{array}$ & 1.25 million & $\begin{array}{l}252,000 \text { diverted } \\
159,000 \text { consumed }\end{array}$ & $\begin{array}{l}20,000 \text { diverted } \\
13,000 \text { consumed }\end{array}$ \\
\hline Ely (1968) & 2 million & 500,000 & 25,000 \\
\hline DOI $(1968)^{\mathrm{a}}$ & 1 million & $\begin{array}{l}\text { 145,000 diverted } \\
61,000-96,000 \text { consumed }\end{array}$ & $\begin{array}{l}\text { 14,500 diverted } \\
6,100-9,600 \text { consumed }\end{array}$ \\
\hline DOI (1973a) & 50,000 underground mine & 8,700 & 17,400 \\
\hline & 100,000 surface mine & 16,800 & 16,800 \\
\hline & 50,000 in-situ & 4,400 & 8,800 \\
\hline & 400,000 technology mix & 65,000 & 16,300 \\
\hline & 1 million technology mix & 155,000 & 15,500 \\
\hline McDonald (1980) & 1.5 million & 200,000 & 13,300 \\
\hline RAND (2005) & \multicolumn{2}{|c|}{$\begin{array}{l}\text { No specific value given; assume } 3 \text { bbl of water per } 1 \text { bbl } \\
\text { of oil }\end{array}$} & 14,125 \\
\hline BLM (2008) & 50,000 mine & $\begin{array}{l}\text { 6,100-9,400 diverted } \\
4,900-7,400 \text { consumed }\end{array}$ & $\begin{array}{l}12,200-18,800 \text { diverted } \\
9,800-14,800 \text { consumed }\end{array}$ \\
\hline- & 200,000 in situ & $\begin{array}{l}7,100-28,200 \text { diverted } \\
18,600-34,600 \text { consumed }\end{array}$ & $\begin{array}{l}\text { 3,550-14,100 diverted } \\
2,700-10,700 \text { consumed }\end{array}$ \\
\hline
\end{tabular}

${ }^{\mathrm{a}}$ These references were not specifically viewed by the authors of this report. The data were published in DOI (1973a).

Sources: Veil and Puder (2006) and BLM (2008)

The estimates vary somewhat. The water required for in-situ production is substantially less than that required for surface or underground mining followed by surface retorting. Nevertheless, the estimates published over 50 years with varying assumptions are all in the same order of magnitude.

\subsection{Water Quality Concerns from Heavy Oil Production}

Heavy oil production creates significant disturbances or disruptions of underground formations, groundwater hydrology, and land surface. Consequently, it affects the quality of ground and surface water resources at the production location and often in adjacent areas too. The combination of geographic location, hydrologic setting, heavy oil type, the extraction technology used, and production rates contribute to the types, severity, and duration of impacts. 


\subsubsection{Groundwater Quality Concerns}

Several aspects of heavy oil production are likely to cause changes in groundwater quality. Surface mining removes overburden rock and exposes it to precipitation and atmospheric oxygen. Chemical changes may occur, and the resulting leachate can affect groundwater.

In underground mining, operators must continuously pump the excavation to allow access to the shale seams. In addition to causing a lowering of groundwater levels, this can allow possible influx of groundwater from lower aquifers. The lower aquifers generally have poorer water quality (e.g., they are higher in total dissolved solids) that can mix with the shallower, higherquality aquifers.

For surface retorted shale, the spent shale is either stockpiled on the surface, where it can come in contact with precipitation, or is placed back into the mine. Spent shale will have more pore space than the original shale, thereby allowing a much greater opportunity for infiltration of precipitation or groundwater. Because of increased porosity and surface area of the spent material, leaching of any naturally present metals or salts in this material would be increased. The resulting leachate can contaminate aquifers. Spent oil sands require disposal following processing. Like the spent shale, they may result in leaching to groundwater.

For in situ shale retorting, the spent shale is left in place, but its porosity is greater than that of the natural oil shale. Leaching of contaminants is likely. For in situ viscous oil and oil sands production, the formations are likely to be in contact with steam or solvents that will eventually reach the groundwater in the area. In situ operations may result in residual hydrocarbons or chemicals (e.g., solvents) in the retorted zone after recovery operations have ceased. The effect of drilling, blasting, and in situ retorting could increase the permeability of the formation, resulting in altered groundwater flow. Leaching of any residual hydrocarbons, salt, or metals would have the potential to increase above natural rates due to increased surface area within the formation.

Lindner-Lunsford et al. (1990) found some organic contaminants in groundwater following an in situ oil shale retorting experiment. In an earlier study, Bethea et al. (1983) evaluated inorganic leachate constituents from in situ retorted oil shale. They reported that the amount of material leached depended on a variety of factors. The retort temperature had the greatest effect on leachate composition. The researchers also concluded that the leaching of retorted oil shale is complex and difficult to study in a laboratory.

Residual organic compounds are also expected to be present in oil sand formations following in situ processing. In a laboratory study, Raphaelian et al. (1981) analyzed water samples obtained from two in situ tar sands experiments and found various organic compounds. Steam from injection can also dissolve organics and metals from source rocks, potentially contaminating groundwater.

The upgrading process should not cause much impact on groundwater. Retorted hydrocarbons from either surface or in situ production methods are sent to a separate upgrading facility on the surface. The upgrading process takes place in an industrial facility similar to a refinery. Unless 
the upgrading facility allows incoming or processed shale oil to leak or spill, there is little opportunity for groundwater impacts.

One of the best documented examples of the effect of oil shale mining on regional groundwater quality is described in a doctoral thesis (Erg 2005). This document describes ground and surface water conditions in an area of Estonia that has produced oil shale from underground mines since the early 1900s. The key provision is that groundwater levels in the mines dropped during production but returned within three years of concluding production. Groundwater quality diminished substantially during production. It too, improved following the end of production but did not reach pre-mining quality. Nevertheless, the groundwater met Estonian drinking water standards. More discussion of Erg's findings is available in Veil and Puder (2006).

Veil and Puder (2006) also provide summaries of several Society of Petroleum Engineers papers that relate to groundwater impacts from production of oil shale and tar sands. Although several hundred papers were found through online searches of the SPE library, only a few were relevant; all of those were from the early 1980s.

\subsubsection{Surface Water Quality Concerns}

Surface water impacts can result from several aspects of oil shale and oil sands development. The need for large volumes of water is likely to draw down local stream levels such that aquatic habitats may be diminished.

Stormwater runoff from disturbed surface areas at mines, spent shale and oil sands piles, access roads, and supporting facilities will carry contaminants into surface waters. Various construction activities (e.g., access roads, building construction, spoil disposal piles, mining or other recovery operations, power line construction) would expose fresh soil to intensified surface runoff caused by precipitation, as well as to wind erosion, leading to increases in sediment and salt contributions to streams.

Removal of surface vegetation can change runoff rates and increase erosion. Increased erosion could also occur due to altered natural drainages, causing concentrated natural runoff. Surface stockpiles of mine tailings or spent material (e.g., oil sand, oil shale) from a retort may be sources of contamination due to salts, metals, and hydrocarbons for both surface and groundwater. Underground mining, though having less of an overall surface impact, would nevertheless require a large amount of space for the stockpiling of raw and spent material as well as for the mine opening and supporting facilities.

Processing of oil sands from mining operations uses a great deal of water and generates large volumes of wastewater. Dusseault (2001) notes that the wastewater has to be treated by flocculation, filtering, or long-term pond settling to remove solids, and because the supernatant water is chloride-rich, it must be disposed of in salt caverns or in deep injection wells. Alternatively, if an injection disposal operation is located nearby, or if a permitted well is available, the dirty process water could be directly injected into a suitable stratum without further treatment. The retorting and upgrading steps can also contribute chemical-laden wastewater. 
Scott et al. (2008) report on tests of ozonation of the oil sand process water to remove organic compounds like naphthenic acids. Ozonation was effective in reducing the concentration of naphthenic acids and eliminating aquatic toxicity from the process water.

Dewatering of mines will require disposal of large amounts of water. The increase in local population associated with the workforce will generate sewage and other domestic and commercial wastewater. To the extent that these wastewaters are inadequately treated before discharge to surface waters, they can cause water quality impacts. In addition to metal and organic contaminants that may be part of discharged oil shale or oil (tar) sands wastewater or runoff, salinity is an important consideration. Most of the U.S. oil shale and tar sands resources are located within the Colorado River watershed. Excess salinity is a major concern in the Colorado River, and eliminating it is one of the key water goals of the Bureau of Reclamation. Oil shale production would contribute to increased salinity.

Contamination of surface water and shallow groundwater could also arise due to runoff or accidental spills or leaks of chemicals or products.

\subsubsection{Surface Water/Groundwater Interactions}

Groundwater and surface water are connected through the hydrologic cycle. Impacts on one type of water may affect the other type of water too. For example, leaching at the surface may impact surface water directly and may also reach shallow groundwater. Contaminants in the groundwater, including those at in situ retort zones, backfilled (and re-saturated) mines, etc., have the potential to travel to springs or seeps. Impact to surface water may also be realized as subsurface discharge of groundwater, depending on site-specific hydrologic conditions.

\subsection{Water Rights}

Chapter 4 describes how important water is to heavy oil production. Production cannot proceed without water. However, water is not always readily available. In the western United States, the available water resources are subject to complicated water rights provisions and may already be allocated for other purposes. Producers would need to obtain water rights allowing them to proceed with development.

Each U.S. state has its own procedures for granting water rights. Veil et al. (2007) describes the types of water rights allocation systems used in the United States. In most states, groundwater rights relate to ownership of the overlying land surface. Several subcategories of systems have developed: absolute dominion (English rule or rule of capture), reasonable use (American rule), restatement of torts, and correlative rights (common resource rule). Other states separate water rights from the rights of land ownership. Groundwater belongs to the state, and any rights are based on specific administrative authorization. Those jurisdictions follow the law of prior appropriation.

It is often difficult to determine a state's particular type of groundwater rights system. The courts and legislatures in the different jurisdictions have crafted specific exceptions and limitations to the various rules. Further, administrative permitting systems as well as local and regional groundwater management and conservation schemes can modify the traditional rule frameworks (Veil et al. 2007). 


\subsection{Water Regulatory Programs}

The previous section summarized the need to obtain authorization to use water. Disposal of water also requires regulatory approval. In the United States, discharge of wastewater to surface water bodies requires a National Pollutant Discharge Elimination System (NPDES) permit. Injection of fluids (either for production activities or for disposal) requires a permit or other approval through the U.S. EPA's Underground Injection Control (UIC) program. Both of these federal programs can be delegated to states that have the interest and legal authorities to take over the programs. Most U.S. states with heavy oil production have already received NPDES and UIC delegated authority.

This report does not give the details of federal, state, or provincial water regulations. Readers are referred to chapters 4 and 5 of Veil and Puder (2006) for more detailed discussion of the specific regulations in the United States and Alberta. 


\section{Chapter 5 - Findings and Conclusions}

Traditionally, heavy oil is presumed to cover viscous liquid oils and oil sands (called tar sands in the United States). As a general rule, heavy oil has an API gravity of less than $22^{\circ}$. In this report we also include oil shale as a form of heavy oil. Heavy oil production has occurred historically in a few prominent locations throughout the world (e.g., Canada, Venezuela, and California). As the price of crude oil has risen dramatically over the past year or two, interest in producing heavy oil has escalated such that other countries are exploring their heavy oil resources.

Heavy oil can be produced by many methods, as described in Chapter 3. Oil sands and oil shale can be produced through surface mining, and oil shale can also be obtained through subsurface mining. The recovered materials are then processed at the surface. In situ methods extract heavy oil directly from the underground formation. Some methods rely on thermal treatment through steam injection, electrical heating, or underground combustion. Other methods use solvents, gas injection, or water to move heavy oil to collection wells. Some technologies rely on vertical wells, while others use horizontal wells. As experience grows in using advanced technologies, operators may utilize more than one technology sequentially in the same field to recover additional resources.

Water is used for various process and non-process purposes at heavy oil production facilities. Examples of process uses include:

- Water for mining and drilling operations,

- Boiler feedwater for steam production,

- $\quad$ Cooling of equipment,

- Washwater and other water used to remove bitumen from oil sands,

- Dust control,

- Water for water flooding, and

- Hydrofracturing of formations.

The non-process uses of water include:

- $\quad$ Drinking water,

- $\quad$ Sanitary (toilets, showers, laundries),

- $\quad$ Power production, and

- $\quad$ Irrigation water during land reclamation.

Chapter 4 provides estimates of the large volumes of water needed to support different types of heavy oil operations. Water availability can be a limiting factor in producing heavy oil, particularly in arid regions. Heavy oil production can affect both ground and surface water quality and quantity. Water recovered from steam injection projects and water used to wash bitumen contains a variety of contaminants that must be treated before the water can be reused or disposed.

In conclusion, heavy oil will be produced in increasing amounts to supplement diminishing light crude oil supplies. Technologies for producing heavy oil are available. New technologies are 
emerging to recover additional heavy oil resources left behind by the traditional production methods. Water availability is a necessary ingredient to allow heavy oil production. Operators will need to evaluate water supplies concurrently with oil reserves before initiating new projects. Likewise, additional energy is needed to produce heavy oil. Operators must also consider the availability of energy when planning new projects. 


\section{References}

Al-Sikaiti, S.H., and J. Regtien, 2008, “Challenging Conventional Wisdom, Waterflooding Experience on Heavy Oil Fields in Southern Oman," presented at the World Heavy Oil Congress 2008, Edmonton, Alberta, Canada, March 10-12.

Bethea, R.M., et al., 1983, "Effect of Groundwater and pH Modification on Quality of Leachate from Simulated In-Situ Retorted Utah Oil Shale,” Society of Petroleum Engineers Journal, SPE 10628 (Oct.):809-819.

BLM, 2008, Proposed Oil Shale and Tar Sands Resource Management Plan Amendments to Address Land Use Allocations in Colorado, Utah, and Wyoming and Final Programmatic Environmental Impact Statement, Bureau of Land Management, FES 08-32, September. Available at http://ostseis.anl.gov/documents/dpeis/index.cfm, accessed August 7, 2008.

Brost, D.F., 2002, "Water Quality Monitoring at the Kern River Field," presented at the 2002 Ground Water Protection Council Produced Water Conference, Colorado Springs, CO, Oct. 16-17. Available at http://www.gwpc.org/meetings/meetings_special/PW02/Papers/Dale_Brost_PWC2002.pdf.

Cobanoglu, M., 2001, "A Numerical Study to Evaluate the Use of WAG as an EOR Method for Oil Production Improvement at B. Kozluca Field, Turkey,” SPE 72127, presented at the SPE Asia Pacific Improved Oil Recovery Conference, 6-9 October, Kuala Lumpur, Malaysia.

Cogliandro, J., 2006, personal communication from Cogliandro (Raytheon Mission Innovations, Tewksbury, Mass.) to R. Kolpa (Argonne National Laboratory, Argonne, Ill.), May 30.

Collins, P.M., M.B. Dusseault, D. Dorscher, and E. Kuebler, 2008, "Implementing CHOPS in the Karazhanbas Heavy Oil Field, Kazakhstan," presented at the World Heavy Oil Congress 2008, Edmonton, Alberta, Canada, March 10-12.

Curtis, C., R. Kopper, E. Decoster, A. Guzman-Garcia, C. Huggins, L. Knauer, M. Minner, N. Kupsch, L.M. Linares, H. Rough, and M. Waite, 2002, "Heavy Oil Reservoirs," Schlumberger Oilfield Review, 14(3) pp. 30-51, Autumn. Available at http://www.slb.com/media/services/resources/oilfieldreview/ors02/aut02/p30_51.pdf.

DOE, 1982, Western Oil-Shale Development: A Technology Assessment, Volume 2, Technology Characterization and Production Scenarios, PNL-3830, prepared by Pacific Northwest Laboratory, Richland, Wash.

DOE, 2004, Strategic Significance of America's Oil Shale Resource, Volume II - Oil Shale Resources, Technology and Economics, prepared by AOC Petroleum Support Services for U.S. Department of Energy, Office for Petroleum Reserves and Office of Naval Petroleum and Oil Shale Reserves, March. Available at http://www.fossil.energy.gov/programs/reserves/npr/publications/npr_strategic_significancev2.pdf. 
DOI, 1973a, Final Environmental Assessment for the Prototype Oil Shale Leasing Program, Volume 1 - Regional Impacts of Oil Shale Development, U.S. Department of Interior, August. Available at

http://ostseis.anl.gov/documents/docs/PrototypeEIS/1973PrototypeOilShaleLeasingEISVol1.pdf.

DOI, 1973b, Final Environmental Assessment for the Prototype Oil Shale Leasing Program, Volume 3 - Specific Impacts of Oil Shale Development, U.S. Department of Interior, August. Available at

http://ostseis.anl.gov/documents/docs/PrototypeEIS/1973PrototypeOilShaleLeasingEISVol3.pdf.

Dusseault, M.B., 2001, “CHOPS: Cold Heavy Oil Production with Sand in the Canadian Heavy Oil Industry,” prepared for Alberta Department of Energy, November, 301 pp.

Dusseault, M.B., 2008a, personal communication between Dusseault, University of Waterloo, Ontario, Canada, and J.A. Veil, Argonne National Laboratory, June 26. Professor Dusseault provided a series of lectures on different aspects of heavy oil that he uses for teaching workshops and courses. Many of the figures used in this report are taken from graphical images included in these lectures.

Dusseault, M.B., 2008b, "Reservoir Enhancements and Production Technology Sequencing," presented at the World Heavy Oil Congress 2008, Edmonton, Alberta, Canada, March 10-12.

Dusseault, M.B., A. Zambrano, J.R. Barrios, and C. Guerra, 2008, "Estimating Technically Recoverable Reserves in the Faja Petrolifera del Orinoco - FPO,” presented at the World Heavy Oil Congress 2008, Edmonton, Alberta, Canada, March 10-12.

Dyni, J.R., 2006, “Geology and Resources of Some World Oil-Shale Deposits,” USGS Scientific Investigations Report 2005-5294, June. Available at http://pubs.usgs.gov/sir/2005/5294/pdf/sir5294_508.pdf, accessed July 28, 2008.

Ely, N., 1968, The Oil Shale Industry's Water Problems, Journal of Petroleum Technology, March, pp. 237-240.

Erg, K., 2005, Groundwater Sulphate Content - Changes in Estonian Underground Oil Shale Mines, doctoral thesis, Tallin University of Technology, May. Available at http://digi.lib.ttu.ee/archives/2005/2005-10/1130350340.pdf.

Greaves, M., C. Ayasse, and A.T. Turta, 2008, "In Situ Upgrading Potential of the CAPRI"TM Process,” presented at the World Heavy Oil Congress 2008, Edmonton, Alberta, Canada, March 10-12.

Hart Energy, 2006, “In Situ Production Technologies,” published as a supplement to Hart Energy publications E\&P Magazine and Oil and Gas Investor, July. Available at http://www.heavyoilinfo.com/feature_items/e-p_heavyoil_article-1.pdf/download, accessed July 29, 2008. 
Inizan, M., Y. Alves, E. Cermeno, E. Draoui, and Y. Gamez, 2008, "Water Production in Extra Heavy Oil Environment: Controlling the Risks, Optimizing the Production,” presented at the World Heavy Oil Congress 2008, Edmonton, Alberta, Canada, March 10-12.

Isaacs, E., and J-Y. Yuan, 2008, "Enhancing Heavy Oil Recovery Using Foam Injection in Applications to Cyclic Steam Stimulation,” presented at the World Heavy Oil Congress 2008, Edmonton, Alberta, Canada, March 10-12.

Kristoff, B.J., K.D. Knorr, C.K. Preston, K. Worth, and R. Sawatzky, 2008, “Joint Implementation of Vapour Extraction - Heavy Oil Recovery Process,” presented at the World Heavy Oil Congress 2008, Edmonton, Alberta, Canada, March 10-12.

Kus, J., 2008, "Extra Heavy Oil in Canada, Water Management Challenges with Steam Assisted Gravity Drainage Developments,” presented at the TEKNA conference, Stavanger, Norway, January 23.

Lindner-Lunsford, J.B., et al., 1990, Effects of In-Situ Oil-Shale Retorting on Water Quality near Rock Springs, Wyoming, Volume I: Final Report, U.S. Geological Survey, Cheyenne, Wyo., prepared for U.S. Department of Energy, Dec.

McDonald, J.W., 1980, The Availability of Water for Oil Shale Development in the Upper Colorado River Basin, SPE 9314, presented at the 55th Annual Technical Conference and Exhibition of the Society of Petroleum Engineers.

Mejia-Caña, L.V., S.J. Sjølyst, E. Gilje, E. Ivarrud, and J. Alvestad, 2008, "Strategies to Improve SAGD Performance in Top Water Reservoirs,” presented at the World Heavy Oil Congress 2008, Edmonton, Alberta, Canada, March 10-12.

Meyer, R.F., and E.D. Attanasi, 2003, "Heavy Oil and Natural Bitumen - Strategic Petroleum Resources,” USGS Fact Sheet 70-03, August. Available at http://pubs.usgs.gov/fs/fs07003/fs070-03.html, accessed July 23, 2008.

Mikula, R.J., V.A. Munoz, and O. Omotoso, 2008, "Water Use in Bitumen Production: Tailings Management in Surface Mined Oil Sands,” presented at the World Heavy Oil Congress 2008, Edmonton, Alberta, Canada, March 10-12.

Mohanty, K.K., 2004, “Development of Shallow Viscous Oil Reserves in North Slope,” DOE Report DE-FC26-01BC15186, prepared for the U.S. Department of Energy, National Energy Technology Laboratory, 122 pp. Available at http://www.netl.doe.gov/technologies/oilgas/publications/WebFactSheets/15186UofHouFinRep.pdf, accessed July 25, 2008.

OSDC, undated, “Alberta’s Vast Resource: The Biggest Known Oil Reserve in the World!,” fact sheet prepared by the Oil Sands Discovery Center. Available at http://www.oilsandsdiscovery.com/oil_sands_story/pdfs/vastresource.pdf, accessed July 28, 2008. 
Portelance, S.N., 2008, “Waste Water Treatment Options for SAGD Oil Production Facilities," presented at the World Heavy Oil Congress 2008, Edmonton, Alberta, Canada, March 10-12.

RAND Corporation, 2005, Oil Shale Development in the United States, prepared by J.T. Bartis, T. LaTourrette, L Dixon, D.J. Peterson, and G. Cecchine, RAND Corporation, for the U.S. Department of Energy, National Energy Technology Laboratory. Available at http://www.rand.org/pubs/monographs/2005/RAND_MG414.pdf, accessed July 28, 2008.

Raphaelian, L.A., et al., 1981, Organic Constituents in Process Water from Tar-Sand Oil Recovery, ANL/PAG-6, Argonne National Laboratory, Argonne, Ill., Aug.

Raytheon, 2006, Raytheon Radio Frequency/Critical Fluid Oil Extraction Technology Fact Sheet. Available at http://www.raytheon.com/newsroom/feature/oil_shale06/. Accessed May 16, 2008.

Ritzius, D.E., S.F. Hodgkins, W.F. Guerard, Jr., E.R. Wilkinson, and D. Lande, 1993, "California Oil, Gas, and Geothermal Resources — an Introduction, fifth edition, prepared by the California Department of Conservation, Division of Oil, Gas, and Geothermal Resources, 81 pp. Available at ftp://ftp.consrv.ca.gov/pub/oil/publications/tr03.pdf, accessed July 23, 2008.

Scott, A.C., W. Zubot, M.D. MacKinnon, D.W. Smith, and P.M. Fedorak, 2008, "Ozonation of Oil Sands Process Water Removes Naphthenic Acids and Toxicity,” Chemosphere 71(1):156-160.

Stettner, M., 2003, personal communication between Stettner, California Department of Conservation, Sacramento, CA, and J. Veil, Argonne National Laboratory, Washington, DC, Feb. 13.

Veil, J.A., and M.G. Puder, 2006, "Potential Ground Water and Surface Water Impacts from Oil Shale and Tar Sands Energy-Production Operations,” ANL/EVS/R-06/9, prepared for the Ground Water Protection Council, October, $50 \mathrm{pp}$. Available at http://www.ead.anl.gov/pub/dsp_detail.cfm?PubID=2030.

Veil, J.A., D. Elcock, N. Ranek, and M.G. Puder, 2007, “Chapter 32: Legal Framework for Groundwater Protection in the United States,” 32 pp. in Handbook of Groundwater Engineering, 2nd edition, edited by J.W. Delleur, CRC Press, Boca Raton, FL.

Waldron, J., 2005, “Produced Water Reuse at the Kern River Oil Field,” Southwest Hydrology, November/December, pp. 26-27. 

Argonne

Environmental Science Division

Argonne National Laboratory

9700 South Cass Avenue, Bldg. 900

Argonne, IL 60439-4867

www.anl.gov

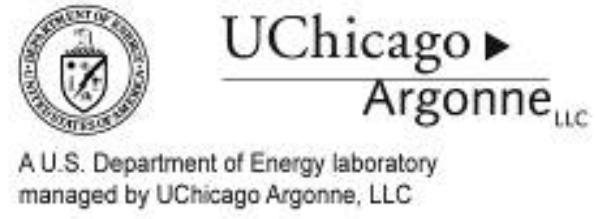

